\title{
Global priority areas for ecosystem restoration
}

https://doi.org/10.1038/s41586-020-2784-9

Received: 14 August 2019

Accepted: 8 September 2020

Published online: 14 October 2020

Check for updates

\author{
Bernardo B. N. Strassburg ${ }^{1,2,3,4} \bowtie$, Alvaro Iribarrem $^{1,2}$, Hawthorne L. Beyer ${ }^{5}$, \\ Carlos Leandro Cordeiro, ${ }^{1,2}$, Renato Crouzeilles ${ }^{1,2,3}$, Catarina C. Jakovac ${ }^{1,2,6}$, \\ André Braga Junqueiraa, 1,2, , Eduardo Lacerda ${ }^{1,2,8}$, Agnieszka E. Latawiec 1,2,9,10, Andrew Balmford"1, \\ Thomas M. Brooks ${ }^{12,13,14}$, Stuart H. M. Butchart ${ }^{11,15}$, Robin L. Chazdon ${ }^{2,16,17,18}$, Karl-Heinz Erb ${ }^{19}$, \\ Pedro Brancalion $^{20}$, Graeme Buchanan ${ }^{21}$, David Cooper ${ }^{22}$, Sandra Díaz ${ }^{23}$, Paul F. Donald ${ }^{1115,21}$, \\ Valerie Kapos ${ }^{24}$, David Leclère ${ }^{25}$, Lera Miles ${ }^{24}$, Michael Obersteiner ${ }^{25,26}$, Christoph Plutzar ${ }^{19,27}$, \\ Carlos Alberto de M. Scaramuzza ${ }^{2}$, Fabio R. Scarano ${ }^{3} \&$ Piero Visconti ${ }^{25}$
}

\begin{abstract}
Extensive ecosystem restoration is increasingly seen as being central to conserving biodiversity ${ }^{1}$ and stabilizing the climate of the Earth ${ }^{2}$. Although ambitious national and global targets have been set, global priority areas that account for spatial variation in benefits and costs have yet to be identified. Here we develop and apply a multicriteria optimization approach that identifies priority areas for restoration across all terrestrial biomes, and estimates their benefits and costs. We find that restoring $15 \%$ of converted lands in priority areas could avoid $60 \%$ of expected extinctions while sequestering 299 gigatonnes of $\mathrm{CO}_{2}-30 \%$ of the total $\mathrm{CO}_{2}$ increase in the atmosphere since the Industrial Revolution. The inclusion of several biomes is key to achieving multiple benefits. Cost effectiveness can increase up to 13-fold when spatial allocation is optimized using our multicriteria approach, which highlights the importance of spatial planning. Our results confirm the vast potential contributions of restoration to addressing global challenges, while underscoring the necessity of pursuing these goals synergistically.
\end{abstract}

The effects of ecosystem degradation and conversion on biodiversity and climate have driven ambitious targets for ecosystem restoration at national, regional and global levels. The United Nations (UN) has declared 2021-2030 the 'UN Decade on Ecosystem Restoration', and the Bonn Challenge and the New York Declaration on Forests aim to restore 350 million hectares worldwide by 2030 . The conservation of the remaining natural ecosystems remains the most important focus to safeguard biodiversity ${ }^{3,4}$, but the large-scale restoration of ecosystems is seen as pivotal to limiting both climate change ${ }^{2}$ and species extinction ${ }^{1}$. Ecosystem restoration includes the restoration of converted lands back into healthy ecosystems, as well as the restoration of degraded ecosystems ${ }^{5}$. Under the Paris Climate Accord, 137 countries highlighted restoration in their plans, and 196 countries agreed to the Convention on Biological Diversity Aichi Biodiversity Target 15 on ecological restoration.
Restoration benefits and costs vary markedly across space. A previous global assessment of areas where trees could be planted indicated there is considerable scope for carbon drawdown ${ }^{6}$, but afforestation of nonforest biomes is likely to have negative consequences for native biodiversity ${ }^{7,8}$. Analyses within regions ${ }^{9}$, or subsets of habitat types ${ }^{10}$ or ecoregions ${ }^{11}$, suggest restoration could be achieved at relatively low $\operatorname{cost}^{12}$ and identify overlaps between priority areas for different objectives $^{10}$-but also indicate considerable trade-offs among these objectives $^{9}$. In contrast to the assessment of priorities for conservation of remaining natural habitats ${ }^{12-14}$, a global analysis of priority areas for restoration has not yet been conducted and the interplay between multiple restoration objectives and biomes remains unknown.

We developed a multicriteria approach for optimizing several outcomes of restoration (biodiversity conservation, the mitigation of climate change and costs) that explicitly accounts for biome-specific

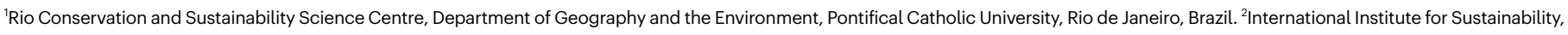
Rio de Janeiro, Brazil. ${ }^{3}$ Programa de Pós Graduacão em Ecologia, Universidade Federal do Rio de Janeiro, Rio de Janeiro, Brazil. ${ }^{4}$ Botanical Garden Research Institute of Rio de Janeiro, Rio de Janeiro, Brazil. ${ }^{5}$ School of Biological Sciences, University of Queensland, St Lucia, Queensland, Australia. ${ }^{6}$ Forest Ecology and Management Group, Wageningen University, Wageningen, The Netherlands. Institut de Ciència i Tecnologia Ambientals, Universitat Autònoma de Barcelona, Barcelona, Spain. ${ }^{8}$ Department of Geography, Fluminense Federal University, Niterói, Brazil.

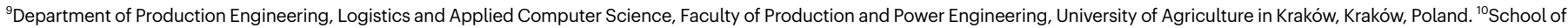

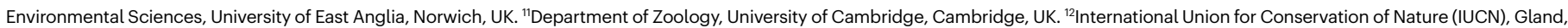

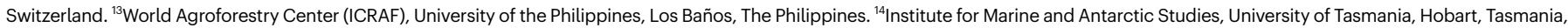
Australia. ${ }^{15}$ BirdLife International, Cambridge, UK. ${ }^{16}$ Department of Ecology and Evolutionary Biology, University of Connecticut, Storrs, CT, USA. ${ }^{17}$ World Resources Institute, Global Restoration

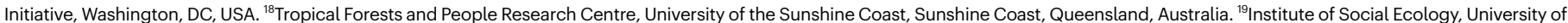

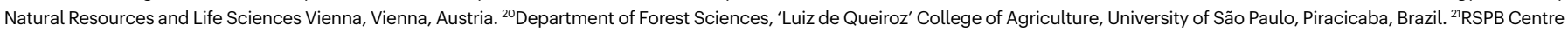
for Conservation Science, Royal Society for the Protection of Birds, Edinburgh, UK. ${ }^{22}$ Secretariat of the Convention on Biological Diversity (SCBD), Montreal, Quebec, Canada. ${ }^{23}$ Instituto Multidisciplinario de Biología Vegetal, CONICET and Universidad Nacional de Córdoba, Córdoba, Argentina. ${ }^{24}$ UN Environment World Conservation Monitoring Centre, Cambridge, UK.

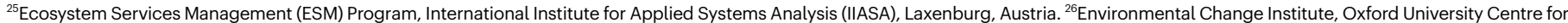
the Environment, Oxford, UK. ${ }^{27}$ Division of Conservation Biology, Vegetation Ecology and Landscape Ecology, University of Vienna, Vienna, Austria. ${ }^{\circledR e-m a i l: ~ b . s t r a s s b u r g @ i i s-r i o . o r g ~}$ 
a

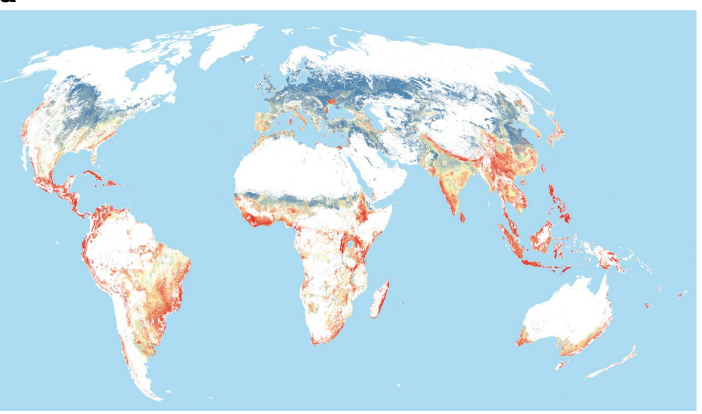

c

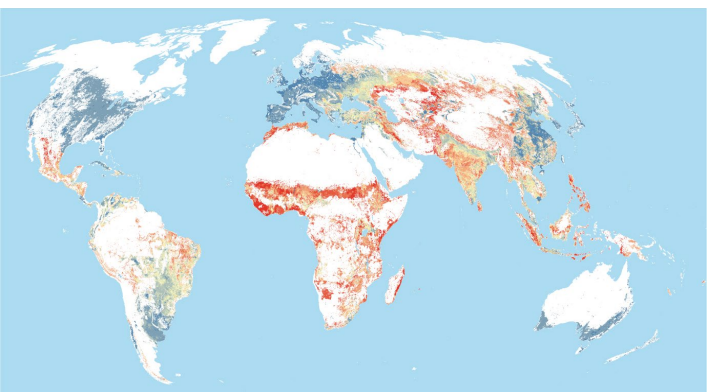

e

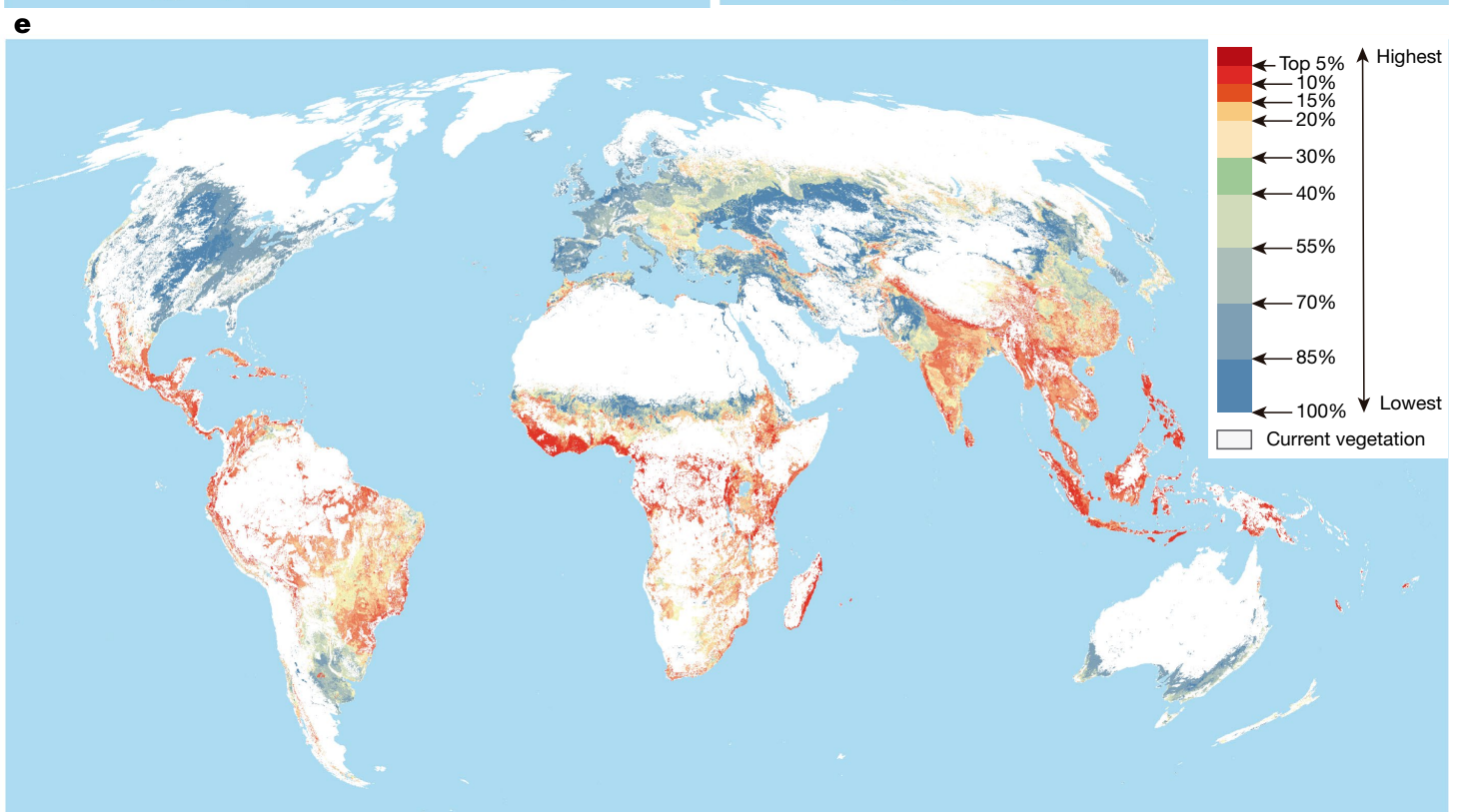

b

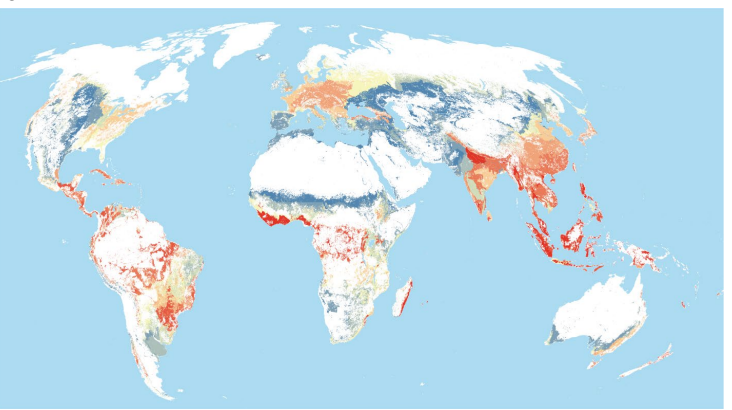

d

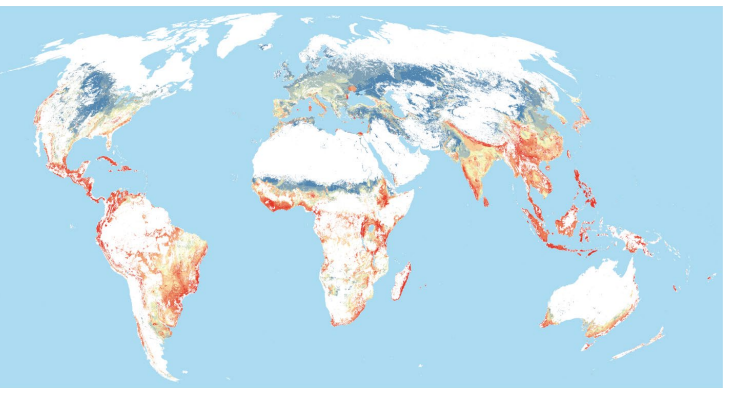

\section{.}


Benefits for biodiversity were quantified as the reduction in potential extinction debt from habitat loss following ecosystem restoration, assessed individually for 20,319 species of mammals, amphibians and birds. Our approach incorporated complementarities among planning units and nonlinearities in the relation between habitat extent and extinction risk $^{9,21-23}$. Species range maps ${ }^{24}$, and altitudinal and habitat preferences ${ }^{24}$, were used to develop an area of habitat ${ }^{25}$ for each species (Methods). Restored areas within the area of habitat of each species were assumed to become habitat for that species in the long-term, thereby reducing extinction risk (Extended Data Fig. 2a). Eight per cent $(1,666)$ of the assessed species are expected to become extinct under current habitat conditions (Methods)-similar to a recent estimate from the Intergovernmental Science-Policy Platform on Biodiversity and Ecosystem Services (IPBES) Global Assessment ${ }^{1}$, of $\mathbf{9 \%}$ of species committed to extinction. Benefits for the mitigation of climate change were measured by long-term carbon dioxide sequestration following restoration to a reference ecosystem structure in each geographical zone, considering above- and belowground biomass ${ }^{26}$ and soil carbon ${ }^{27}$ (Extended Data Fig. 2b, Methods). Opportunity costs from agriculture were measured by the net present value of future profits that are potentially foregone by restoring cropland or pastureland back to native vegetation (Methods). To estimate total costs, we added restoration implementation costs by adjusting estimates from a Brazilian study ${ }^{9}$ according to the labour and input costs of each country (Extended Data Fig. 2c, Methods).

\section{Priority areas for restoration, and outcomes}

Priority areas for restoration that focus solely on biodiversity, climate change mitigation or cost minimization (Fig. 1a-c) have different spatial patterns, which result in widely variable restoration outcomes. Benefits for biodiversity, estimated as reductions in extinction debt, vary sixfold for the same area restored (the reduction in extinction debt for $5 \%$ restoration varies from 7 to $43 \%$ ) (Fig. 2a). Benefits for the mitigation of climate change vary threefold (sequestration of 48-130 gigatonnes of $\mathrm{CO}_{2}$ under $5 \%$ restoration) (Fig. $2 \mathrm{~b}$ ). To match the extinction reduction benefits of a biodiversity-focused $15 \%$ target, restoration focused on minimizing costs would require restoring $50 \%$ of converted lands globally (Fig. 2a). Variation can also be seen in the distribution of priority areas across all 17 IPBES subregions (Extended Data Fig. 3).

Restoring $15 \%$ of converted lands globally (consistent with Aichi Biodiversity Target 15 ) could reduce the current global extinction debt by $63 \pm 4 \%$ if concentrated in priority areas for biodiversity (Figs. 2a, 3). If focused on the mitigation of climate change, up to $335 \pm 35$ gigatonnes of $\mathrm{CO}_{2}$ could be sequestered (Figs. 2b, 3)-equivalent to $34 \%$ of the total increase in atmospheric $\mathrm{CO}_{2}$ since the Industrial Revolution (about AD 1750). These figures are higher than those often reported for restoration $^{2,28}$, which use average carbon stocks and do not consider spatial optimization.

Although single-criterion solutions do not perform well for the other criteria, multicriteria solutions can deliver a substantial fraction of both sets of benefits simultaneously. The biodiversity-focused solution of the $15 \%$ target delivers $73 \%$ of potential climate-mitigation gains, whereas the climate-focused solution provides only $65 \%$ of the potential biodiversity gains. Optimizing for both benefits simultaneously ('biodiversity + climate' scenario in Fig. 1d) would deliver $95 \%$ of the maximum biodiversity benefit and $89 \%$ of the maximum for climate change mitigation (scenario III in Fig. 3).

Introducing cost minimization as an extra objective of the optimization markedly improves the cost effectiveness of solutions (trade-off curve with point $V$ in Fig. 3) consistent with previous studies ${ }^{9,15}$. The environmental solutions that do not include cost minimization in the optimization lead to the highest costs of all unconstrained scenarios (up to US $\$ 5,835 \pm 870$ per hectare). The solution that minimizes costs (scenario IV in Fig. 3 ) is considerably cheaper (US $\$ 2,356 \pm 563$ per hectare),
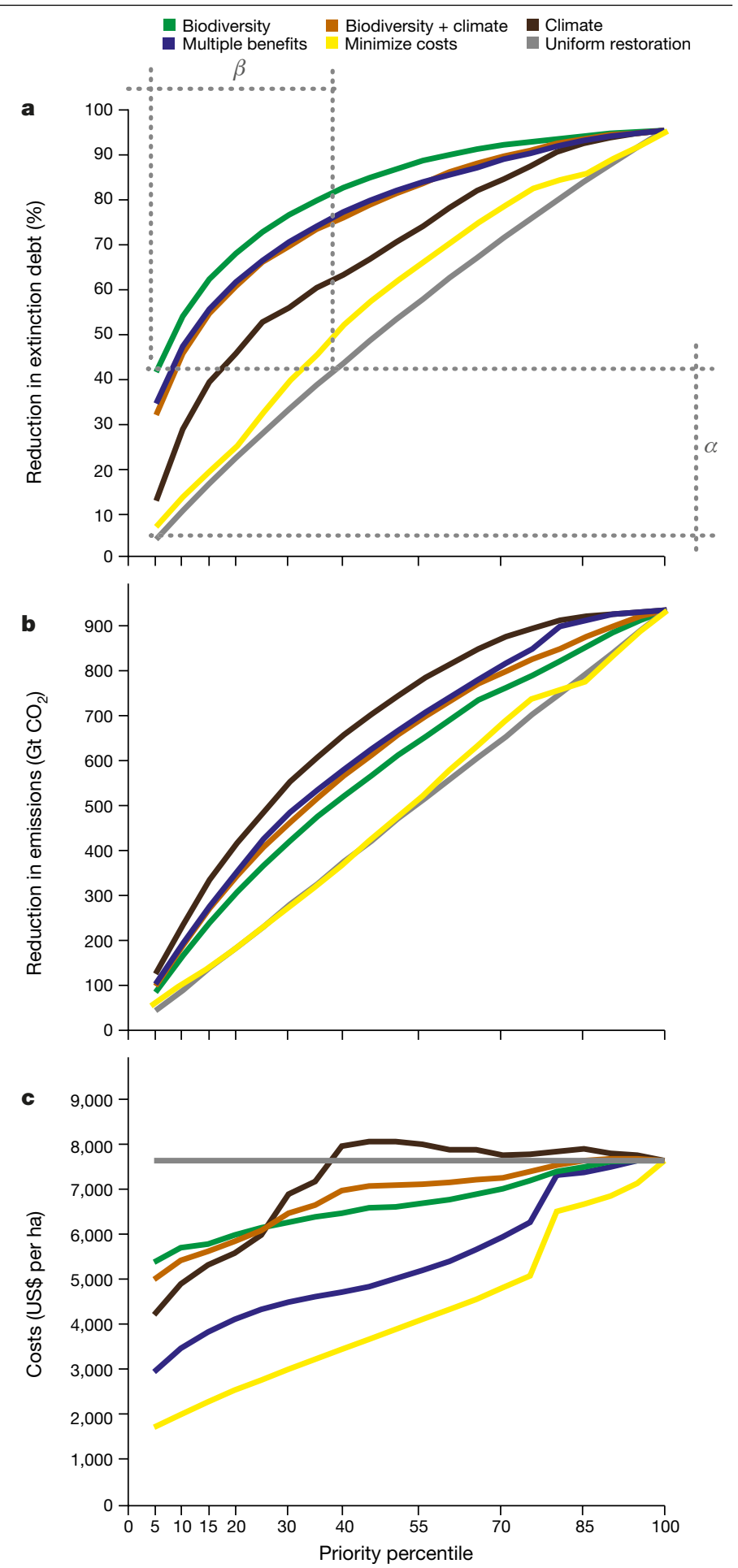

Fig. 2 Outcomes of restoration for biodiversity, mitigating climate change and minimizing opportunity costs. a-c, Outcomes for biodiversity (a), the mitigation of climate change (b) and minimizing opportunity costs (c). In each graph, outcomes are presented for five selected scenarios across our three criteria: maximize biodiversity benefits (green), maximize climate change mitigation (black), maximize biodiversity and climate benefits simultaneously (brown), minimize opportunity cost (yellow) and multiple benefits (blue). The grey line represents outcomes of a restoration that is uniformly dispersed across all areas, as a benchmark for no spatial prioritization. The results highlight the substantial variation in outcomes for the same area target, illustrated in a by the sixfold difference in outcomes for biodiversity $(\alpha)$ for the same $5 \%$ restoration target depending on the criteria chosen for the spatial allocation of restoration. 


\section{Article}

but in environmental terms performs very poorly, delivering only $34 \%$ and $39 \%$, respectively, of the potential benefits for biodiversity and climate. Solving the optimization for all three criteria simultaneously provides cost-effective multicriteria solutions. One of these, the 'multiple benefits' scenario (Fig. 1e), would- at 5\% restoration-increase cost effectiveness for biodiversity by 13 -fold when compared with a 'uniform' restoration scenario (discussed below). At $15 \%$ restoration (scenario V in Fig. 3), this scenario would deliver 91\% of the potential benefit for biodiversity and $82 \%$ of that for climate, while reducing costs by $27 \%$ compared to the biodiversity + climate scenario, reinforcing previous findings that optimizing for several benefits can yield valuable compromise solutions ${ }^{9,16}$.

Our results confirm that ecosystem restoration can have a major role in the mitigation of climate change at relatively low costs. Although it takes time for restored ecosystems to reach carbon stocks of reference conserved ecosystems, tropical forests (which make up most of the area of restored ecosystems in all but the 'minimize costs' scenarios) return to $90 \%$ of reference carbon stocks in 66 years and to $>50 \%$ in the first 20 years (both median times) ${ }^{29}$. Biomass corresponds to $92 \%$ of the sequestered carbon estimate, and soil to the remaining $8 \%$. Across the main scenarios, carbon prices of US $\$ 10-15$ per tonne of $\mathrm{CO}_{2}$ would be sufficient to cover costs in targets up to $45 \%$ of global converted area (Extended Data Fig. 4), which could deliver climate mitigation benefits of as much as $702 \pm 83$ gigatonnes of $\mathrm{CO}_{2}$. This lies at the lower end of mitigation cost options according to the Intergovernmental Panel on Climate Change (IPCC) ${ }^{2}$ and below the 2019 market price in the EU trading scheme (US $\$ 25$ per tonne of $\mathrm{CO}_{2}$ equivalent). That said, we emphasize that restoration efforts need to be accompanied by strong reductions in fossil fuel emissions ${ }^{28}$.

\section{The relative contribution of ecosystem types}

Our analysis highlights the value of considering several biomes simultaneously, as these ecosystems vary in their relative contribution to the criteria chosen. Of 2,870 million hectares of converted lands we identified worldwide, we estimate that $54 \%$ were originally forests, $25 \%$ grasslands, $14 \%$ shrublands, $4 \%$ arid lands and $2 \%$ wetlands (Extended Data Fig. 5). Validation of the estimated original ecosystem type using data from 1992-2015 indicates high predictive accuracy (total root mean square error of $6.73 \%$ ), consistent across all vegetation classes (Extended Data Fig. 6, Methods). Nevertheless, our approach probably underestimates the original extent of ecosystems that have suffered disproportionally high historical losses, such as wetlands.

Wetlands and forests are of the highest relative importance for biodiversity conservation (Fig. $4 \mathrm{a}$ ) and the mitigation of climate change (Fig. 4b), respectively. The focus shifts to arid ecosystems and grasslands when the goal is to minimize costs (Fig. 4c). When targeting all three outcomes, all biomes have an important role (Fig. 4d). Joint priority areas for biodiversity and climate are concentrated in wetlands and tropical and subtropical forests with high carbon stocks, high diversity and marked loss of natural habitat, and are generally located ${ }^{10}$ in biodiversity hotspots $\mathrm{s}^{30}$. Converted areas within relatively intact tropical forests are also priorities for the mitigation of climate change, and South American and African shrublands are additional priorities for biodiversity (Fig. 1).

\section{Scale and feasibility constraints}

The unconstrained global scenarios are useful benchmarks and might support international incentive schemes such as REDD+ ('reducing emissions from deforestation and forest degradation' ${ }^{22}$ ), yet involve some regions having high proportions of their converted lands prioritized for restoration. For example, $96 \%$ of the Caribbean converted lands are in the top $15 \%$ of global priorities for biodiversity (Extended Data Fig.3). Therefore, we investigated the effects of achieving global

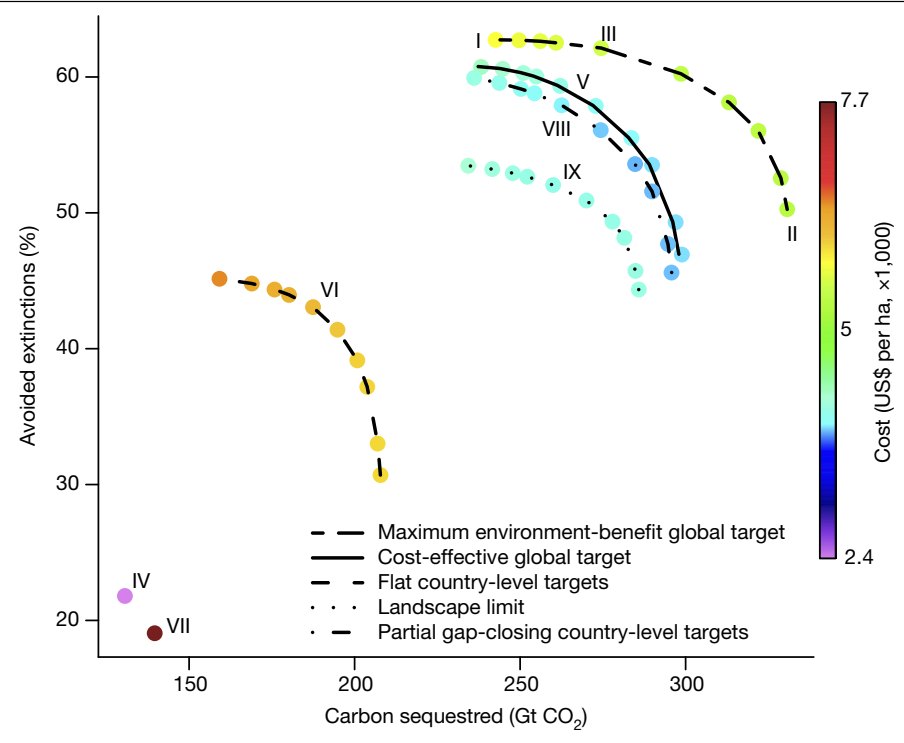

Fig. 3 | Outcomes for species conservation, the mitigation of climate change and costs for selected scenarios. The following scenarios are shown: maximum biodiversity benefits (I); maximum climate benefits (II); biodiversity + climate (III); minimum costs (IV); multiple benefits (V); multiple benefits with $15 \%$ national cap (VI); multiple benefits with $15 \%$ landscape cap (VII); multiple benefits in spared lands at national level (VIII); and multiple benefits in spared lands at landscape level (IX). The five lines connect scenarios in the same group, corresponding to global unconstrained biophysical-only (no cost) frontier, global unconstrained cost-effective frontier, national-level spared-lands cost-effective, landscape-level spared-lands cost-effective and national-level 15\%-cap frontier (from outer rightmost to inner leftmost). The concave shape of these trade-off curves suggests the potential for compromise options in the middle of the curves.

restoration targets while accounting for geopolitical boundaries, landscape constraints and the land-sparing potential of improved land use. First, we simulated each country restoring $15 \%$ of its converted lands. Second, we simulated achieving this target dispersed at a finer landscape level, treating our $25-\mathrm{km}^{2}$ planning units as landscapes and restoring $15 \%$ of the converted lands in each one. Third, for both these levels, we limited restoration up to the area potentially spared by closing $75 \%$ of current yield gaps for all crop types (considering only rain-fed attainable yields) (Extended Data Fig. 7) and livestock production (Methods). The rationale is that increasing agricultural yields can spare lands for restoration while maintaining or increasing overall agricultural production (a concept termed 'land-neutral ecological restoration ${ }^{31}$ ), and investigated at several scales ${ }^{23,32}$.

Applying the $15 \%$ restoration target at the national scale would result in a $28 \%$ reduction in benefits for biodiversity and $29 \%$ for climate while increasing costs by $52 \%$ (scenario $\mathrm{VI}$ in Fig. 3 ) in the multiple benefits scenario, when compared to the global unconstrained equivalent. Up to $61 \%$ of the global priority areas (mostly in the tropics; red in Extended Data Fig. 8) would not be restored in these national-level scenarios, although they could potentially be targeted by international incentive schemes such as REDD+. Constraining targets so that all landscapes are restored by $15 \%$ (scenario VII in Fig. 3) would reduce biodiversity benefits by $67 \%$ and the benefits of climate change mitigation by $49 \%$, while increasing costs by $92 \%$. This more-dispersed restoration could have benefits in terms of increased representation of ecological communities and local benefits of nature to people ${ }^{33,34}$. National and local implementation plans should consider these trade-offs.

In comparison with scenarios that uniformly constrain restoration to a fixed $15 \%$ of national or landscape units, implementing restoration in priority areas while maintaining current agricultural production via achievable yield increases would result in far greater environmental 


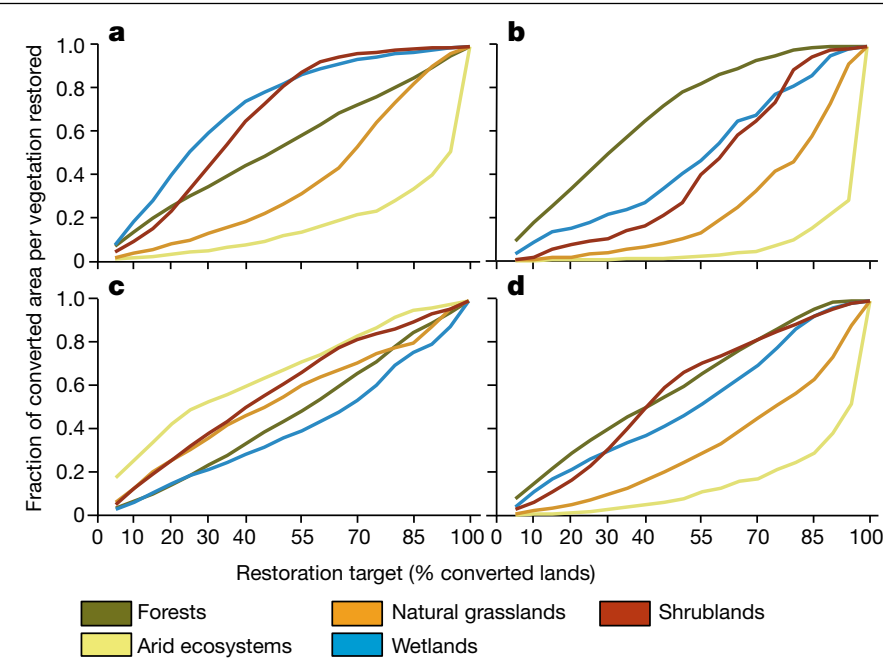

Fig. 4 | The role for various criteria of the distribution of major ecosystem types that could be restored. a-d, Fraction of converted area per ecosystem type that would need to be restored to meet increasing targets when focusing on the scenarios of biodiversity (a), mitigating climate change (b), minimizing opportunity cost (c) and all three criteria (d). The results highlight the substantial variation in the relative importance that each ecosystem type has depending on the objective(s) of restoration, which suggests that restoration initiatives aimed at multiple objectives should include several types of ecosystem.

benefits and lower costs. At national levels, outcomes would be within $3 \%$ or less of the unconstrained global scenarios (scenario VIII in Fig. 3), whereas at landscape levels biodiversity benefits would drop by $12 \%$ only (scenario IX in Fig. 3), instead of $67 \%$ in the uniform scenario. At the global level, $55 \%$ of converted lands could be restored while maintaining current production. These values suggest the potential for more ambitious restoration beyond the $15 \%$ Aichi Biodiversity Target 15 and highlight the substantial scope for a restoration approach implemented through integrated landscape management to provide marked environmental benefits while limiting conflicts with agriculture. Although agricultural intensification can have detrimental effects on climate, biodiversity and human health ${ }^{2,35-39}$, yields can often be increased without incurring these costs ${ }^{37}$.

We focused our analysis on current land use, based on a scenario in which current remnants of natural ecosystems are successfully retained. The sensitivity of our analysis to this assumption was tested on our central multiple benefits scenario, using a pessimistic land-use change scenario with substantial habitat loss (Methods). The results show that the overall distribution of restoration would be very similar (total root mean square error of $13 \%$ ), and differences in outcomes for biodiversity, carbon sequestration and costs are all within the margin of error for the estimates based on current land-use change (Extended Data Fig. 9).

\section{Discussion}

Our results demonstrate that differences in the spatial heterogeneity of restoration benefits and costs leads to substantial variation in outcomes depending on the prioritization criteria used. These varied spatial patterns in turn underscore the need to adopt multicriteria approaches that incorporate several ecosystem types. The framework used in this analysis - which we have named PLANGEA-is already supporting parties to the Convention on Biological Diversity in exploring targets for a post-2020 biodiversity framework and informing restoration planning in Brazil, with the incorporation of custom-made criteria for different biomes that range from water quality benefits in the Atlantic forest to poverty reduction through job creation in the
Caatinga biome. Applying decision-support tools at regional, national and local levels can provide further insight for restoration planning and implementation, and address local socio-ecological contexts. These processes must incorporate the free, prior and informed preferences and knowledge of Indigenous peoples and local communities to foster success and resilience and avoid negative social outcomes ${ }^{40}$. Importantly, restoration should not happen at the expense of the conservation of remaining natural ecosystems, which is the most cost-effective action in most cases ${ }^{41}$.

Our analysis has many limitations. First, it carries the uncertainties associated with the input data, particularly those associated with global land-cover maps ${ }^{26}$, species ranges (although using the area of habitat for species limits overestimation of their occurrence ${ }^{25,42,43}$ ) and carbon estimates (Extended Data Fig. 10, Methods). Second, our approach to estimating the original vegetation cover might underestimate the original coverage of some ecosystems, although our estimates fall within ranges found in the literature ${ }^{5}$ and validation analyses indicated high accuracy (Extended Data Fig. 6). Following previous publications ${ }^{14,44-46}$, and owing to global-level data limitations, we used only three vertebrate classes (those for which all species distributions have been mapped, and habitat and altitudinal preferences are available) as a proxy for biodiversity benefits, which is a limitation both in terms of species representativeness and genetic- and ecosystem-level biodiversity benefits. However, extinction-risk levels in these groups are broadly comparable to those for incompletely assessed groups ${ }^{4}$. Our analysis focuses only on habitat-related extinction risk and assumes that recolonization of restored habitat is possible, provided it falls within the ranges of species when-in practice-many other threatening processes must be addressed ${ }^{47}$ and species-specific management may be required to foster species recovery. We focused exclusively on converted areas, but the restoration of degraded ecosystems that have not been fully cleared can also provide important benefits ${ }^{5}$. We did not consider future projections of climate change, which would affect spatial distributions of species, as well as biomass and agricultural production, and the contribution and value of restoration to ecosystem-based adaptation. Finally, this work does not consider important socio-economic issues that could affect restoration prioritization (for example, social equity and cultural priorities) and the operationalization of restoration (for example, land tenure and sociopolitical context $)^{48-50}$, which should be appropriately addressed at local and regional scales through culturally inclusive decision-making and implementation.

\section{Conclusions}

Our findings provide useful insights for research and policy in five main ways. First, they quantify the potential for, and outcomes of, ambitious restoration targets to deliver biodiversity conservation and the mitigation of climate change. These gains are most marked if coupled with ambitious goals for retaining natural ecosystems ${ }^{4}$ within landscape approaches that integrate conservation, restoration and improved use of agricultural lands. For instance, combining the retention of remaining natural ecosystems with the restoration of $30 \%$ of converted lands in priority areas would mitigate $71 \pm 4 \%$ of current extinction debt while sequestering $465 \pm 59$ gigatonnes of $\mathrm{CO}_{2}$-equivalent to $49 \%$ of all of the $\mathrm{CO}_{2}$ increase in the atmosphere since the Industrial Revolution. This could form a basis for ambitious 2050 global conservation and climate mitigation agendas.

Second, our findings highlight that area alone is an ineffective metric for ensuring substantial biodiversity and climate mitigation outcomes, with up to sixfold variation in outcomes for the same restored area; targets should instead be oriented towards overarching outcomes, such as extinction avoidance and the mitigation of climate change. Third, at a time at which many restoration targets are forest-focused, our results highlight the importance of including several biomes. Fourth, we show the complementary roles that different countries 


\section{Article}

have in meeting overarching global targets, highlighting the benefits of international cooperation. Fifth, by quantifying and mapping the efficiency gains of joint climate and biodiversity prioritization, our findings underscore the synergies that arise from bridging the aims of the three UN Rio Conventions rather than pursuing their objectives in isolation. The coupled challenges that these conventions address are some of the greatest faced by humankind, but our declared collective ambition to restore nature-if well-planned and implemented-can make substantial headway towards addressing them.

\section{Online content}

Any methods, additional references, Nature Research reporting summaries, source data, extended data, supplementary information, acknowledgements, peer review information; details of author contributions and competing interests; and statements of data and code availability are available at https://doi.org/10.1038/s41586-020-2784-9.

1. IPBES. Global Assessment Report on Biodiversity and Ecosystem Services of the Intergovernmental Science-Policy Platform on Biodiversity and Ecosystem Services (IPBES Secretariat, 2019).

2. IPCC. An IPCC Special Report on Climate Change, Desertification, Land Degradation, Sustainable Land Management, Food Security, and Greenhouse Gas Fluxes In Terrestrial Ecosystems (SRCCL) (World Meteorological Organization, 2019).

3. Di Marco, M., Ferrier, S., Harwood, T. D., Hoskins, A. J. \& Watson, J. E. M. Wilderness areas halve the extinction risk of terrestrial biodiversity. Nature 573, 582-585 (2019).

4. Maron, M., Simmonds, J. S. \& Watson, J. E. M. Bold nature retention targets are essential for the global environment agenda. Nat. Ecol. Evol. 2, 1194-1195 (2018)

5. IPBES. The IPBES Assessment Report on Land Degradation and Restoration (IPBES Secretariat, 2018).

6. Bastin, J. F. et al. The global tree restoration potential. Science 365, 76-79 (2019).

7. Chazdon, R. \& Brancalion, P. Restoring forests as a means to many ends. Science $\mathbf{3 6 5}$ 24-25 (2019).

8. Temperton, V. M. et al. Step back from the forest and step up to the Bonn challenge: how a broad ecological perspective can promote successful landscape restoration. Restor. Ecol. 27, 705-719 (2019).

9. Strassburg, B. B. N. et al. Strategic approaches to restoring ecosystems can triple conservation gains and halve costs. Nat. Ecol. Evol. 3, 62-70 (2019).

10. Brancalion, P. H. S. et al. Global restoration opportunities in tropical rainforest landscapes. Sci. Adv. 5, eaav3223 (2019).

11. Mappin, B. et al. Restoration priorities to achieve the global protected area target. Conserv. Lett. 12, e12646 (2019).

12. Brooks, T. M. et al. Global biodiversity conservation priorities. Science 313, 58-61 (2006).

13. Joppa, L. N., Visconti, P., Jenkins, C. N. \& Pimm, S. L. Achieving the convention on biological diversity's goals for plant conservation. Science 341, 1100-1103 (2013).

14. Montesino Pouzols, F. et al. Global protected area expansion is compromised by projected land-use and parochialism. Nature 516, 383-386 (2014).

15. Ando, A., Camm, J., Polasky, S. \& Solow, A. Species distributions, land values, and efficient conservation. Science 279, 2126-2128 (1998).

16. Naidoo, R. et al. Global mapping of ecosystem services and conservation priorities. Proc. Natl Acad. Sci. USA 105, 9495-9500 (2008)

17. Beyer, H. L., Dujardin, Y., Watts, M. E. \& Possingham, H. P. Solving conservation planning problems with integer linear programming. Ecol. Modell. 328, 14-22 (2016).

18. Cabeza, M. \& Moilanen, A. Design of reserve networks and the persistence of biodiversity. Trends Ecol. Evol. 16, 242-248 (2001)

19. European Space Agency. Climate Change Initiative (ESA CCI). https://www.esa-landcovercci.org/?q=node/158 (accessed May 2018)

20. Veldman, J. W. et al. Where tree planting and forest expansion are bad for biodiversity and ecosystem services. Bioscience 65, 1011-1018 (2015).
21. Thomas, C. D. et al. Extinction risk from climate change. Nature 427, 145-148 (2004).

22. Strassburg, B. B. N. et al. Impacts of incentives to reduce emissions from deforestation on global species extinctions. Nat. Clim. Chang. 2, 350-355 (2012).

23. Strassburg, B. B. N. et al. Moment of truth for the Cerrado hotspot. Nat. Ecol. Evol. 1, 0099 (2017).

24. IUCN. The IUCN Red List of Threatened Species. Version 2019-3 http://www.iucnredlist. org (accessed 10 December 2019).

25. Brooks, T. M. et al. Measuring terrestrial area of habitat $(\mathrm{AOH})$ and its utility for the IUCN Red List. Trends Ecol. Evol. 34, 977-986 (2019).

26. Erb, K.-H. et al. Unexpectedly large impact of forest management and grazing on global vegetation biomass. Nature 553, 73-76 (2018).

27. Sanderman, J., Hengl, T. \& Fiske, G. J. Soil carbon debt of 12,000 years of human land use. Proc. Natl Acad. Sci. USA 114, 9575-9580 (2017).

28. IPCC. in Global Warming of $1.5^{\circ} \mathrm{C}$ (eds Masson-Delmotte, V. et al.) 3-24 (World Meteorological Organization, 2018).

29. Poorter, L. et al. Biomass resilience of Neotropical secondary forests. Nature 530, 211-214 (2016).

30. Myers, N., Mittermeier, R. A., Mittermeier, C. G., da Fonseca, G. A. \& Kent, J. Biodiversity hotspots for conservation priorities. Nature 403, 853-858 (2000).

31. Strassburg, B. B. N. et al. Increasing Agricultural Output While Avoiding Deforestation-A Case Study for Mato Grosso, Brazil (International Institute for Sustainability, 2012).

32. Latawiec, A. E., Strassburg, B. B. N., Brancalion, P. H. S., Rodrigues, R. R. \& Gardner, T. Creating space for large-scale restoration in tropical agricultural landscapes. Front. Ecol. Environ. 13, 211-218 (2015).

33. Anderson, C. B. et al. Determining nature's contributions to achieve the sustainable development goals. Sustain. Sci. 14, 543-547 (2019).

34. Martín-López, B. et al. Nature's contributions to people in mountains: a review. PLoS ONE 14, e0217847 (2019)

35. Latawiec, A. E., Strassburg, B. B. N., Valentim, J. F., Ramos, F. \& Alves-Pinto, H. N. Intensification of cattle ranching production systems: socioeconomic and environmental synergies and risks in Brazil. Animal 8, 1255-1263 (2014).

36. Newbold, T. et al. Global effects of land use on local terrestrial biodiversity. Nature $\mathbf{5 2 0}$ 45-50 (2015).

37. Balmford, A. et al. The environmental costs and benefits of high-yield farming. Nat. Sustain. 1, 477-485 (2018)

38. Garnett, T. et al. Sustainable intensification in agriculture: premises and policies. Science 341, 33-34 (2013).

39. Erb, K.-H. et al. Exploring the biophysical option space for feeding the world without deforestation. Nat. Commun. 7, 11382 (2016).

40. Reyes-García, V. et al. The contributions of Indigenous Peoples and local communities to ecological restoration. Restor. Ecol. 27, 3-8 (2019).

41. Possingham, H. P., Bode, M. \& Klein, C. J. Optimal conservation outcomes require both restoration and protection. PLoS Biol. 13, e1002052 (2015).

42. Beresford, A. et al. Minding the protection gap: estimates of species' range sizes and holes in the protected area network. Anim. Conserv. 14, 114-116 (2011).

43. Rondinini, C. et al. Global habitat suitability models of terrestrial mammals. Phil. Trans. $R$. Soc. Lond. B 366, 2633-2641 (2011)

44. Di Marco, M. et al. Synergies and trade-offs in achieving global biodiversity targets. Conserv. Biol. 30, 189-195 (2016).

45. Betts, M. G. et al. Global forest loss disproportionately erodes biodiversity in intact landscapes. Nature 547, 441-444 (2017).

46. Venter, O. et al. Targeting global protected area expansion for imperiled biodiversity. PLoS Biol. 12, e1001891 (2014).

47. Joppa, L. N. et al. Filling in biodiversity threat gaps. Science 352, 416-418 (2016).

48. Knight, A. T., Cowling, R. M. \& Campbell, B. M. An operational model for implementing conservation action. Conserv. Biol. 20, 408-419 (2006).

49. Ban, N. C. et al. A social-ecological approach to conservation planning: embedding social considerations. Front. Ecol. Environ. 11, 194-202 (2013).

50. Halpern, B. S. et al. Achieving the triple bottom line in the face of inherent trade-offs among social equity, economic return, and conservation. Proc. Natl Acad. Sci. USA 110, 6229-6234 (2013).

Publisher's note Springer Nature remains neutral with regard to jurisdictional claims in published maps and institutional affiliations.

(c) The Author(s), under exclusive licence to Springer Nature Limited 2020 


\section{Methods}

No statistical methods were used to predetermine sample size. The experiments were not randomized and investigators were not blinded to allocation during experiments and outcome assessment.

We applied a multicriteria optimization framework (PLANGEA) to identify global priority areas for restoration and quantify trade-offs and synergies across biodiversity, climate change mitigation and costs. To do so, we: (i) estimated current converted areas worldwide and their original (before human settlement) ecosystem type; (ii) estimated potential long-term restoration benefits for climate change mitigation; and (iii) biodiversity in these areas; (iv) estimated costs; (v) implemented a multicriteria optimization algorithm based on linear programming; and (vi) simulated different global restoration scenarios based on area targets. Our study area includes all terrestrial regions of the Earth from $-80^{\circ}$ to $80^{\circ}$ latitude and from $-180^{\circ}$ to $180^{\circ}$ degrees longitude. We divided the study area into 5,590,200 planning units of $4.96 \times 4.96 \mathrm{~km}$ (about $2,500 \mathrm{ha}$ ), used as unit of analysis. The geographic information system analysis used a Mollweide projection to ensure similar pixel sizes across the study area.

\section{Current land use and cover, and original ecosystem type}

We developed two land-use and cover maps: (i) one representing the current land use and cover of the world to identify potential areas available for restoration (hereafter referred to as the current land use and land cover map' (CLULC)) and (ii) one representing the extent of original ecosystem types (that is, the land cover before these areas were converted to croplands, pasturelands or urban areas) to identify the potential type of ecosystem to be restored (hereafter referred to as the 'original ecosystem type map' (OET)). To build the CLULC map, we used the European Space Agency Climate Change Initiative (ESACCI) land use and cover maps ${ }^{19}$ from 1992 and 2015 , with $300 \times 300$-m pixel size. We used the ESA CCI reclassification of its original 37 classes into 10 major CLULC classes, representing 5 ecosystem types (forests, wetlands, arid ecosystems, natural grasslands and shrublands), 2 classes of areas potentially available for restoration (croplands and cultivated grasslands), 2 classes of nonrestorable areas (rock and ice, and urban areas) and 1 class for water bodies. As the ESA CCI map does not distinguish cultivated from natural grasslands, we used the 'Terrestrial Ecoregions of the World ${ }^{51}$ and the 'Gridded Livestock of the World v.2.0 ${ }^{52}$ datasets to classify each pixel into natural (not needing restoration) or cultivated grasslands (potentially restorable pasturelands). If a pixel classified as grasslands (class 130) in the ESA CCI is located within an ecoregion of nongrassland ecosystems (for example, forests), and if it presents a cattle density equal or higher than 1 head per $\mathrm{km}^{2}$, it was reclassified as 'pasturelands' -otherwise, it was reclassified as 'native grassland'.

We built the OET map based on either: (i) the CLULC classes and amount of remaining ecosystem types inside each planning unit (97\% of the total number of planning units) or (ii) using the ecoregion classes for planning units with no remaining native vegetation (3\% of the total). In the first case, we applied the following equation:

$$
\mathrm{OET}_{i}=\mathrm{CET}_{i}+\left(\frac{\mathrm{CAV} \times \mathrm{CET}_{i}}{\mathrm{SET}}\right)
$$

in which $\mathrm{OET}_{i}$ is the percentage of original ecosystem type $i$ in each planning unit; $\mathrm{CET}_{i}$ is the percentage of native ecosystem type $i$ in the CLULC map; CAV is the percentage of anthropic vegetation in each planning unit in the CLULC map (croplands, pasturelands and urban areas); and SET is the sum of the percentages of all original ecosystem types within a planning unit in the CLULC map.

\section{Climate change mitigation}

To estimate the carbon potentially sequestered with restoration, we built a global map of carbon stock change in the above- and belowground biomass and in the soils of restorable areas. To estimate the potential carbon stocks that can accumulate in the long term in above- and belowground biomass after restoration, we used an approach commonly used in global estimates (for example, ref. ${ }^{53}$ ). We sampled maps of current carbon stocks to obtain mean carbon stock values from remaining native vegetation and then extrapolated these values to restorable areas within the same geographical zone based on the 'Terrestrial Ecoregions of the World ${ }^{\text {'51 }}$. We sampled three current carbon stock maps that were built using different approaches for carbon stock estimation, produced by ref. ${ }^{26}$ : maps no. 1, 5 and 6 described in the methods of the original publication ${ }^{26}$. Actual carbon stock map no. 1 is based on typical biomass-stock values from the literature or census statistics assigned to the land-use classes. Actual carbon stock maps no. 5 and 6 correspond, respectively, to grid-cell-based minima and maxima of remote-sensing-derived carbon estimations (for example, refs. ${ }^{54,55}$ ). For a detailed description of the methods used to produce maps of actual carbon stock in the biomass, see ref. ${ }^{26}$.

In each of the three current carbon stock maps, we selected planning units that contained $70 \%$ of native vegetation cover or more, according to ref. ${ }^{56}$, totalling 2,816,055 planning units. The land-cover classes considered as native were: (i) non-productive and snow; (ii) wilderness, no trees; (iii) unused forests; (iv) natural grassland, no trees; and (v) natural grassland with trees. In planning units that are not fully covered with native vegetation, we applied a correction to generate estimates of carbon stock per hectare corresponding exclusively to the remaining native vegetation in that planning unit and not influenced by anthropic land uses. To do so, we used a reference value of 6 tonnes $\mathrm{Cha}^{-1}$ for anthropic land-use (consistent with refs. ${ }^{26,57}$ ) and calculated for each planning unit the carbon stocks per hectare of native vegetation using the formula:

$$
C_{\text {native }}=\frac{\left(C_{\text {total }} \times \mathrm{PU}_{\text {area }}\right)-\left(C_{\text {converted }} \times \text { Area }_{\text {converted }}\right)}{\text { Area }}
$$

in which $C_{\text {native }}$ is the carbon stock per hectare of the native vegetation in a given pixel, $C_{\text {total }}$ is the total carbon stock per hectare in the pixel, $\mathrm{PU}_{\text {area }}$ is the area of the planning unit $\left(10,000\right.$ ha $\left(\right.$ ref. $\left.\left.{ }^{26}\right)\right), C_{\text {converted }}$ is the reference value of carbon stocks per hectare for anthropic land uses

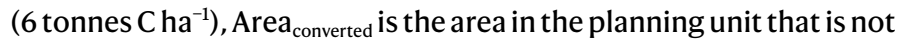
covered by native vegetation, and Area $_{\text {native }}$ is the area in the planning unit covered by native vegetation.

Once the planning units with $\geq 70 \%$ native vegetation were selected, and their $C$ values were corrected for $C_{\text {native, }}$, we defined geographical zones within which these pixels would be sampled, and potential carbon stock values would be estimated. Geographical zones were delimitated by the 'Ecoregions of the World" ${ }^{58}$, containing 848 ecoregions, 14 biomes and 9 realms. Within each delimited geographical zone (ecoregion), we aimed to estimate the maximum carbon stock that could be achieved for each vegetation type; to do so, we performed a calculation that combined information of the distribution of carbon stocks in the pixels of that ecoregion (which were not specific to each vegetation type) with the percentages of each vegetation type in those pixels, according to the CLULC map. For each vegetation type in each ecoregion, we calculated the weighted 95th percentile of the carbon stock values of the pixels (using the function wtd.quantile in the R package $\mathrm{Hmisc}^{59}$ ), in which the weights were the proportion of the respective native vegetation type in those pixels. For example, in a given ecoregion, the potential carbon stocks of grasslands was given by the weighted 95th percentile of the carbon stocks of the pixels in that ecoregion, in which the weights were the percentages of grasslands in each pixel. We chose to use the 95th percentile and not maximum values of the distribution because we aimed to estimate the upper limit of carbon stocks that could be achieved for each vegetation type (95\% of the values in the distribution are lower than the calculated value), while avoiding overestimation of potential carbon stocks owing to outliers with extremely high values 
(following ref. ${ }^{26}$ ). We did these calculations independently for the three current carbon stock maps from ref. ${ }^{26}$ (maps no. 1,3 and 4 from ref. ${ }^{26}$ ), on the basis of which we calculated mean (and s.d.) potential carbon stock values (per hectare) per native vegetation type per ecoregion. In ecoregions with no planning unit containing $\geq 70 \%$ remaining native vegetation (that is, with no sample available for carbon stocks in native vegetation), we calculated the weighted 95 th percentile values from the corresponding intersection of biome and realm ${ }^{51,58}$, which group ecoregions at one level higher. Then, we estimated the potential carbon stocks per hectare in each planning unit (pixel) by multiplying the mean potential carbon stock per hectare by the proportion of each original native vegetation type estimated to cover the pixel after restoration (from the OET map), using the formula:

$$
C_{\text {stock }}=\frac{\sum_{\mathrm{nvt}=i}^{n} C_{\mathrm{nvt}} \times \text { Area }_{\mathrm{nvt}}}{\text { Area }_{\mathrm{nv}}}
$$

in which $C_{\text {stock }}$ is the potential carbon stock per hectare in that planning unit, $i$ is a given native vegetation type (nvt) of which there are $n$ types, $C_{\text {nvt }}$ is the estimated carbon stock per hectare of the native vegetation type in the respective geographical zone, Area $_{\text {nvt }}$ is the area of the native vegetation type estimated to cover the pixel after restoration and Area $_{\mathrm{nv}}$ is the total area in the planning unit estimated to be covered by native vegetation after restoration. Finally, we calculated the change in biomass carbon stock (delta carbon stock) as the difference between the potential and current carbon stocks for restorable areas. For restorable areas, we assumed an average current carbon stock of 6 tonnes $\mathrm{Cha}^{-1}$, on the basis of reference values used by ref. ${ }^{26}$ and recommended by the IPCC guidelines ${ }^{57}$. To estimate uncertainties in potential carbon stocks in the biomass, we used the same approach, but instead of the mean we used the s.d. of the potential carbon stock values (per hectare) per native vegetation type per ecoregion as a basis for our calculations.

In addition to aboveground carbon, we also estimated the delta carbon stock in the soil based on the most comprehensive dataset of soil organic carbon and the predictions for the distribution of soil organic carbon in the present (2010) and pre-settlement land use $(12,000 \text { years ago })^{27}$, according to a spatially explicit database of historic patterns of human land use (HYDE, History Database of the Global Environment ${ }^{60}$ ). Assuming that the restoration of native vegetation would recover soil organic carbon stocks to pre-settlement levels, we subtracted the current soil organic carbon (2010) from the pre-settlement soil organic carbon $(12,000$ years ago) to obtain the delta soil carbon for a soil depth interval of $0-30 \mathrm{~cm}$. In comparison with biomass carbon, it might take longer for soil organic carbon to reach pre-settlement levels ${ }^{61}$. Finally, we summed the delta biomass carbon and delta soil carbon to obtain a total delta carbon stock for the restorable areas in the globe.

Our quantification of potential carbon sequestration-similarly to other approaches (for example, that of the IPCC)-lacks an explicit temporal dimension and does not consider ecosystem feedbacks, but only changes in carbon stocks resulting from land-use change. The recovery of carbon stocks in the soil and in the biomass can be highly variable within and across biomes, taking from a few years to centuries depending on a combination of factors such as land-use type, climatic conditions and soil types ${ }^{29,62}$. Our approach of using as reference levels the carbon stocks of old-growth vegetation (for biomass) and of pre-settlement conditions (for soil) may therefore be an overestimation, especially when short-term carbon sequestration goals are considered. On the other hand, rates of carbon uptake and storage in the biomass and soils can be substantially accelerated; for example, by enhancing species diversity and the presence of late successional species at the onset of restoration ${ }^{63}$. Ecosystem models with an explicit temporal dimension and that incorporate these feedbacks need to be incorporated in large-scale carbon sequestration models to provide more accurate estimations of the potential of restoration for climate change mitigation

After the optimization, we compute uncertainties for the aggregated values of sequestered carbon of a given optimization solution using a linear propagation method, considering these uncertainties originate from systematic differences in the approaches used for the three maps used to generate the s.d. The uncertainties in the aggregated values for the sequestered carbon across the restored area selected in each scenario (CB) are propagated as

$$
\delta \mathrm{CB}=\sum_{i}\left(\frac{\partial \mathrm{CB}}{\partial s_{i}}\right)\left(\delta s_{i}\right),
$$

in which $\delta s_{i}$ is the s.d. of the sequestered-carbon-per-hectare estimates using the three different input maps (as described in 'Multicriteria optimization algorithm') in the planning unit $i$.

These uncertainties are mostly due to the uneven distribution and overall scarcity of field data for modelling and validating carbon stocks in the biomass and soil ${ }^{27,64,65}$. Our potential and current carbon stock estimates (Extended Data Fig. 2b) also have intrinsic uncertainties that are combined when delta carbon values are calculated, and these uncertainties are probably underestimated given the unknown biases introduced by our extrapolation of biomass values from preserved areas to converted lands. Upcoming wall-to-wall datasets, such as those to be expected from missions such as BIOMASS of the ESA or GEDI of NASA may help to reduce uncertainties in potential carbon sequestration and their high spatial variability ${ }^{26}$-in particular if they can be linked to particular land-use activities and robustly cover many ecosystem types. A comparison of our results with those from a previous study shows very high agreement across all biome types (Extended Data Fig. 10).

\section{Biodiversity}

We modelled the change in extinction risk for 5,012 mammals, 6,515 amphibians and 11,121 bird species (totalling 22,648 species). Species distribution maps were accessed from the IUCN Red List ${ }^{24}$ and BirdLife International and Handbook of the Birds of the World ${ }^{66}$. To refine our spatial estimate of current and original habitat for each species, we used data from the IUCN Red List on the elevation ranges and habitat preferences of each species, reclassified to match our five ecosystem types. The resulting distribution of suitable habitat for each species is known as the area of habitat ${ }^{25}$ (also known as the extent of suitable habitat ${ }^{67}$ ). To estimate the potential benefits of restoration to biodiversity, we quantified the reduction in the extinction risk of each species resulting from increases in its area of habitat. We used a function based on the species-area relationship that estimates extinction risk $(r)$ for each species on the basis of the ratio between its current and original habitat extent ${ }^{9,21-23}: r=1-\left(x / A_{0}\right)^{z}$, in which $A_{0}$ is the original area of habitat to the focal species, $x$ is the current area of habitat (which can be increased by restoration), and the power $z$ describes the rate of diminishing returns in value of additional area of habitat at reducing extinction risk. This application of the species-area relationship assumes that likelihood of extinction is a function of the proportion of original habitat remaining for a species, and is silent on absolute amount of habitat, and so may underestimate extinction risk for naturally restricted-range species and overestimate it for widespread ones ${ }^{68}$.

We evaluate reductions in extinction risk using a $z$ value of 0.25 , following refs. ${ }^{9,20-23}$, for our central estimate, and incorporated a variation from 0.15 to 0.35 to derive uncertainty ranges for $r$. To implement this in a linear programming framework, we quantified benefit as the tangent to these curves at a given current area of habitat and updated these benefit values after solving each of the increments of total restoration area target. Hence, if existing area of habitat is small there is a large benefit to increasing that area, but as the area of habitat increases 
there is a diminishing benefit for the addition of more habitat area. This approach assumes that existing habitat will not be destroyed.

After the optimization, the uncertainties on the aggregated values of the reduction of extinction risk (BD) are computed using a standard quadratic propagation, assuming that the value of $z$ for each species will be in the range $0.15-0.35$ with $95 \%$ confidence level,

$$
\delta \mathrm{BD}=\sqrt[2]{\sum_{j}\left(\frac{\partial r_{j}}{\partial z}\right)^{2}(\delta z)^{2}},
$$

assuming an uncertainty $\delta z$ of 0.1 in the value of $z$, for all species $j$.

\section{Costs}

We estimated foregone benefits of agricultural commodities as a proxy for conservation opportunity costs ${ }^{69-71}$. We computed the opportunity costs of agriculture and cultivated pastures separately. For agriculture, we used the extended data of ref. ${ }^{72}$-obtained from the IMPACT model $^{73}$-to get equilibrium-price estimates for 31 commodities in their SSP2 scenario with no climate change considered ('SSP2-NoCC'). The commodities were selected on the basis of data availability for their current and potential productivity, as obtained from $\mathrm{GAEZ}^{74}$. For each commodity selected, we computed the present net value (NPV) of one tonne of their produce for 40 years using a discount rate of $5 \%$ for our central estimate. We used each NPV to convert the ref. ${ }^{74}$ maps of current productivity of each crop in each grid cell from produced quantity per area to production value per area. We assumed a $20 \%$ margin of profit to obtain the opportunity cost for each commodity, as a likely conservative (that is, high) estimate based on profit margins in the USA (non-small farms ${ }^{75}$ ), some EU countries ${ }^{76}$ and Canada ${ }^{77}$. We recognize this is a simplified assumption and that in reality profit margins vary greatly, in particular with farm sizes. We added the resulting maps to obtain the opportunity cost layer for agriculture.

For pasture, we used the stocking rate data from the 'Gridded Livestock of the World v2.0' (ref. ${ }^{52}$ ). We consider pasture to include only the planning units with stocking rates in the range between 0.1 to 20 heads of cow per hectare, assumed to be compatible with pasture-based production. Values below 0.1 heads of cow per hectare were classified as natural grasslands, whereas values above 20 heads of cow per hectare were assumed to be fully confined and therefore not targeted for restoration. We used the values of animal yield per country from the IMPACT model to convert the stocking rate from head per hectare to tonnes of produced beef per hectare per year. We also used the beef NPV from ref. ${ }^{72}$ (also using a 40-year time horizon and a discount rate of $5 \%$ for our central estimate) to convert the previous results to production value per area. Finally, we assumed the same $20 \%$ margin of profit as for croplands (as most data sources ${ }^{75-77}$ reported only aggregate profit margins for all farms) to obtain the opportunity cost for pastures. To obtain the combined opportunity cost layer, we used the average between agriculture and pasture values, weighted by the proportion of each land use with respect to the total area of agriculture and pasturelands in the planning unit.

To account for restoration implementation costs, we used as the basis a cost of US $\$ 2,148$ per hectare from an earlier study for the Atlantic forest $^{9}$, which is the average value for 100 -ha projects across all scenarios, and higher (that is, conservative) than costs for most studies included in the most-extensive global review of restoration costs available $^{78}$. Owing to the absence of spatially explicit data on restoration costs for several biomes, we opted to use the values from the previous application for the Atlantic forest ${ }^{9}$, as that biome-wide estimate reflected implementation costs expected from large-scale restoration planning such as the one being modelled here (in contrast to mostly projected-based costs included in ref. ${ }^{78}$ ). We adjusted these values to all other countries, taking into account their relative costs of agricultural labour $^{79}$ and input (fertilizer ${ }^{80}$ ) in relation to Brazil. We assumed that labour costs accounts for $70 \%$ of the costs and inputs to $30 \%$, on the basis of evidence from Brazilian projects ${ }^{81}$. Although treating implementation costs as constant per country is a simplification, the previous application 9 shows that $87 \%$ of the variation in total costs across scenarios was due to variations in the opportunity costs. The total cost layer (Extended Data Fig. 2c) was obtained by adding the combined opportunity cost layer and the restoration cost layer.

After the optimization, the uncertainties on the aggregated values of the opportunity costs $(\mathrm{OC})$ are propagated from assumed uncertainties in the prices $\delta P$ of $25 \%$, and in the discount rate $\delta$ DR of $5 \%$, which is the same as assuming that the discount rate would be in the range $0-10 \%$. Specifically, we compute the uncertainties in the opportunity costs per hectare $c_{i}$ in each planning unit $i$ as follows

$$
\delta c_{i}=\sqrt[2]{\left(\frac{\partial c_{i}}{\partial P}\right)^{2}(\delta P)^{2}+\left(\frac{\partial c_{i}}{\partial \mathrm{DR}}\right)^{2}(\delta \mathrm{DR})^{2}} .
$$

The final uncertainty in the opportunity costs is then combined as

$$
\delta \mathrm{OC}=\sqrt[2]{\sum_{i}\left(\frac{\partial \mathrm{OC}}{\partial c_{i}}\right)^{2}\left(\delta c_{i}\right)^{2}} .
$$

\section{Areas potentially spared after closing the yield gap}

We estimated areas potentially spared for restoration compatible with maintaining current levels of agricultural production. For croplands, we used yield gaps based on yields attainable without irrigation (rain-fed) from the GAEZ database ${ }^{74}$. For pasturelands, we used the same approach from ref. ${ }^{21}$ to estimate the yield gap for extensive pasturelands systems, also based on rain-fed fodder grass productivity from the GAEZ database $^{74}$. In both cases we assumed that $75 \%$ of the yield gap could be closed in a sustainable manner, following evidence from the literature $^{82-84}$. Our estimate is arguably more conservative as-unlike these sources-we did not consider irrigation. We then capped restoration per geographical level (either landscape or country) to an area compatible with maintaining current agricultural production.

\section{Multicriteria optimization algorithm}

To identify the priority areas for restoration, we ran a multicriteria optimization algorithm on the basis of an objective function that defines the amount of area to be restored in each planning unit aiming to maximize benefits (climate change mitigation and/or biodiversity) and/ or minimize costs (opportunity and restoration costs). The objective function is

$$
\begin{aligned}
& \max \sum_{i}^{n_{\mathrm{p}}} x_{i}\left(\frac{w_{\mathrm{s}} s_{i}+w_{\mathrm{b}} b_{i}}{c_{i}}\right) \\
& \text { subject to } \sum_{i}^{n_{\mathrm{p}}} x_{i} A_{i} \leq T \\
& x_{i} \leq u_{i} \forall_{i} \in n_{\mathrm{p}} \\
& \sum_{j \in M_{a}} x_{j} A_{j} \leq L_{a} \forall_{a} \in n_{\mathrm{c}}
\end{aligned}
$$

in which $x$ is the decision variable representing the proportion of an ecosystem type to be restored within each planning unit $i$. The two components of the objective function represent the returns (benefit or cost) of a type of ecosystem restoration to biodiversity $(b)$ (benefit per US $\$$ per $\mathrm{km}^{2}$ ) summed across all species, and carbon sequestration ( $s$ ) (tonnes per US $\$$ per $\mathrm{km}^{2}$ ), in which the total cost of a type of ecosystem restoration is the sum of opportunity and restoration costs (c) (US $\$$ per $\left.\mathrm{km}^{2}\right) . n_{\mathrm{p}}$ is the total number of planning units. The first constraint limits the total area of habitat to be restored $(A)\left(\mathrm{km}^{2}\right)$, in which $A$ varied depending on the target used for each run. The second 
constraint ensures that the proportion of the planning unit restored ranges from 0 to a maximum value $(u)$, which accounts for the proportion of the planning unit that is already covered by that ecosystem type or represents a land use that cannot be restored (for example, urban areas). The third constraint, which was implemented only in a subset of problems, limits the area of habitat restored within each country $(a)$ to a limit $\left(L_{a}\right)$, in which $n_{\mathrm{c}}$ represents the total number of countries and $M_{a}$ represents the set membership of planning units within countries. The user-defined parameters $w_{\mathrm{b}}$ and $w_{\mathrm{s}}$ weight the relative contribution of the biodiversity and climate change mitigation components, respectively, of the objective function. They are required because the equivalence of objectives with different units is a subjective decision that must be made by decision-makers. The objective function can be solved over a range of relative weights to understand how these components trade-off. The model was solved iteratively in 20 increments of the target area $A$ to approximate the nonlinear function describing biodiversity values (that is, the target was not prioritized at once only). Alternative scenarios involved removal of components of this model, such as the removal of the opportunity costs denominators (c) to maximize benefits regardless of cost, or the addition of further constraints for the scenarios that limited the area of restoration within each country or landscape. Exact solutions to this linear programming problem were found using the software R Symphony version 0.1-28 (ref. ${ }^{85}$ ). Our tool is also capable of optimizing conservation and restoration decision on the basis of a target financial budget, which might be useful for policy and implementation planning. As targets and policies put forward at the global level are area-based, we focused on this type of optimization for the present study.

\section{Scenarios}

We modelled 1,200 scenarios of restoration prioritization, aiming to evaluate trade-offs among climate change mitigation, biodiversity and cost for different restoration targets, geographical constraints and interplay with land potentially spared from agricultural intensification. There are 400 globally unconstrained scenarios ( 20 restoration targets $\times 10$ weights between climate and biodiversity objectives, all of these excluding and including costs); another 400 scenarios investigate the effects of both country- and landscape-level constraints (for the 20 restoration targets and 10 weights, always including costs); the final 400 scenarios investigate the effects of capping restoration to the area made available by closing $75 \%$ of the yield gap (again for all 20 targets and 10 weights, including costs, at both country and landscape scales).

The sensitivity test including future land-use change was performed using the regional rivalry (SSP3) scenario used by the $\mathrm{IPCC}^{86}$, using data available at https://luh.umd.edu/data.shtml.

\section{Reporting summary}

Further information on research design is available in the Nature Research Reporting Summary linked to this paper.

\section{Data availability}

All input datasets are available from the references cited. All output datasets generated during the current study are available from the corresponding author upon request.

\section{Code availability}

$\mathrm{R}$ codes developed for and used in this analysis are available upon request from the corresponding author.

51. Dinerstein, E. et al. An ecoregion-based approach to protecting half the terrestrial realm Bioscience 67, 534-545 (2017).

52. Robinson, T. P. et al. Mapping the global distribution of livestock. PLoS ONE 9, e96084 (2014).
53. Gibbs, H. K., Brown, S., Niles, J. O. \& Foley, J. A. Monitoring and estimating tropical forest carbon stocks: making REDD a reality. Environ. Res. Lett. 2, 045023 (2007).

54. Baccini, A. et al. Estimated carbon dioxide emissions from tropical deforestation improved by carbon-density maps. Nat. Clim. Chang. 2, 182-185 (2012).

55. Saatchi, S. S. et al. Benchmark map of forest carbon stocks in tropical regions across three continents. Proc. Natl Acad. Sci. USA 108, 9899-9904 (2011).

56. Erb, K.-H. et al. A comprehensive global 5 min resolution land-use data set for the year 2000 consistent with national census data. J. Land Use Sci. 2, 191-224 (2007).

57. IPCC. Guidelines for National Greenhouse Gas Inventories (National Greenhouse Gas Inventories Programme, 2006).

58. Olson, D. M. et al. Terrestrial ecoregions of the world: a new map of life on earth: a new global map of terrestrial ecoregions provides an innovative tool for conserving biodiversity. Bioscience 51, 933-938 (2001).

59. Harrell, F. E. Jr et al. Hmisc: Harrell Miscellaneous. R package version 4.1-1. https://cran. r-project.org/web/packages/Hmisc/Hmisc.pdf (2018).

60. Goldewijk, K. K., Beusen, A., Van Drecht, G. \& De Vos, M. The HYDE 3.1 spatially explicit database of human-induced global land-use change over the past 12,000 years. Glob. Ecol. Biogeogr. 20, 73-86 (2011).

61. Fonseca, W. et al. Carbon accumulation in the biomass and soil of different aged secondary forests in the humid tropics of Costa Rica. For. Ecol. Manage. 262, 1400-1408 (2011).

62. Guo, L. B. \& Gifford, R. M. Soil carbon stocks and land use change: a meta analysis. Glob. Change Biol. 8, 345-360 (2002).

63. Yang, Y., Tilman, D., Furey, G. \& Lehman, C. Soil carbon sequestration accelerated by restoration of grassland biodiversity. Nat. Commun. 10, 718 (2019).

64. Mitchard, E. T. et al. Uncertainty in the spatial distribution of tropical forest biomass: a comparison of pan-tropical maps. Carbon Balance Manag. 8, 10 (2013).

65. Hengl, T. et al. SoilGrids $250 \mathrm{~m}$ : global gridded soil information based on machine learning. PLOS ONE 12, e0169748 (2017).

66. BirdLife International \& NatureServe. Bird Species Distribution Maps of the World. Version $2018.1 \mathrm{http}: / /$ datazone.birdlife.org/species/requestdis (BirdLife International and Handbook of the Birds of the World, 2018).

67. Beresford, A. et al. Poor overlap between the distribution of protected areas and globally threatened birds in Africa. Anim. Conserv. 14, 99-107 (2011).

68. Staude, I. R. et al. Range size predicts the risk of local extinction from habitat loss. Glob. Ecol. Biogeogr. 29, 16-25 (2020).

69. Carrasco, L. R., Webb, E. L., Symes, W. S., Koh, L. P. \& Sodhi, N. S. Global economic trade-offs between wild nature and tropical agriculture. PLoS Biol. 15, e2001657 (2017).

70. Naidoo, R \& Iwamura, T. Global-scale mapping of economic benefits from agricultural lands: implications for conservation priorities. Biol. Conserv. 140, 40-49 (2007).

71. Polasky, S. et al. Where to put things? Spatial land management to sustain biodiversity and economic returns. Biol. Conserv. 141, 1505-1524 (2008).

72. Sulser, T. B. et al. in Beyond a Middle Income Africa: Transforming African Economies for Sustained Growth with Rising Employment and Incomes (ReSAKSS Annual Trends and Outlook Report 2014 (eds. Badiane, O. et al.) Ch. 2 (International Food Policy Research Institute (IFPRI), 2014).

73. Robinson, S. et al. The International Model for Policy Analysis of Agricultural Commodities and Trade (IMPACT): Model Description for Version 3 (IFPRI Discussion Paper 1483) (International Food Policy Research Institute (IFPRI), (2015).

74. IIASA \& FAO. Global Agro-ecological Zones (GAEZ v.3.0) (IIASA \& FAO, 2012).

75. Hoppe, R. A. Structure and Finances of U.S. Farms: Family Farm Report (EIB-132) (US Department of Agriculture Economic Research Service, 2014).

76. Baležentis, T. et al. Decomposing dynamics in the farm profitability: an application of index decomposition analysis to Lithuanian FADN sample. Sustainability 11, 2861 (2019).

77. Statistic Canada. Table 32-10-0136-01, Farm Operating Revenues and Expenses, Annual. https://open.canada.ca/data/en/dataset/59ca6332-391b-4fdf-bb3a31e5e45f6bb7 (2008).

78. De Groot, R. S. et al. Benefits of investing in ecosystem restoration. Conserv. Biol. 27 , 1286-1293 (2013).

79. International Labour Organization. ILOSTAT database. https://ilostat.ilo.org/data (accessed March 2020)

80. United Nations Statistics Division. UN Comtrade Database. https://comtrade.un.org/ (accessed March 2020).

81. Brancalion, P. H. S. et al. What makes ecosystem restoration expensive? A systematic cost assessment of projects in Brazil. Biol. Conserv. 240, 108274 (2019).

82. Mueller, N. D. et al. Closing yield gaps through nutrient and water management. Nature 490, 254-257 (2012).

83. Mueller, N. D. et al. Declining spatial efficiency of global cropland nitrogen allocation Glob. Biogeochem. Cycles 31, 245-257 (2017).

84. Foley, J. A. et al. Solutions for a cultivated planet. Nature 478, 337-342 (2011).

85. Hornik, K. et al. SYMPHONY in R, an R interface to the SYMPHONY solver for mixed-integer linear programs. http://R-Forge.R-project.org/projects/rsymphony/ (2019).

86. Popp, A. et al. Land-use futures in the shared socio-economic pathways. Glob. Environ. Change 42, 331-345 (2017).

Acknowledgements B.B.N.S. acknowledges that this work was supported by the Serrapilheira Institute (grant number Serra-1709-19329). We acknowledge inputs from the Secretariat of the Convention of Biological Diversity and experts from the Intergovernmental Science-Policy Platform on Biodiversity and Ecosystem Services. We are very grateful for the support provided by F. Gomes, J. Krieger, I. Leite, R. Capellão, G. Duarte, L. Martinez, L. Oliveira and D. Rocha in the preparation of this manuscript. 
Author contributions B.B.N.S. conceived the study, coordinated the development of the multicriteria approach, led the analyses and wrote the first version of the paper. A.I., H.L.B. and B.B.N.S. led the multicriteria modelling. T.M.B., R.C., R.L.C. and S.H.M.B. helped with the development of the multicriteria approach. A.I., H.L.B., C.L.C., E.L., C.C.J., A.B.J., R.C., K.-H.E. and B.B.N.S. developed input datasets. S.H.M.B., G.B., P.F.D., K.-H.E. and C.P. contributed data. D.C., C.A.d.M.S. and F.R.S. helped with the interface with policy applications. B.B.N.S., A.I., H.L.B., C.L.C., R.C., C.C.J., A.B.J., E.L., A.E.L., A.B., T.M.B., S.H.M.B., R.L.C., P.B., D.C., S.D., V.K., L.M., D.L., M.O. and P.V. analysed the results. All authors provided input into subsequent versions of the manuscript.
Competing interests The authors declare no competing interests.

Additional information

Supplementary information is available for this paper at https://doi.org/10.1038/s41586-0202784-9.

Correspondence and requests for materials should be addressed to B.B.N.S.

Peer review information Nature thanks Simon Ferrier and Robin Naidoo for their contribution to the peer review of this work.

Reprints and permissions information is available at http://www.nature.com/reprints. 


\section{Article}
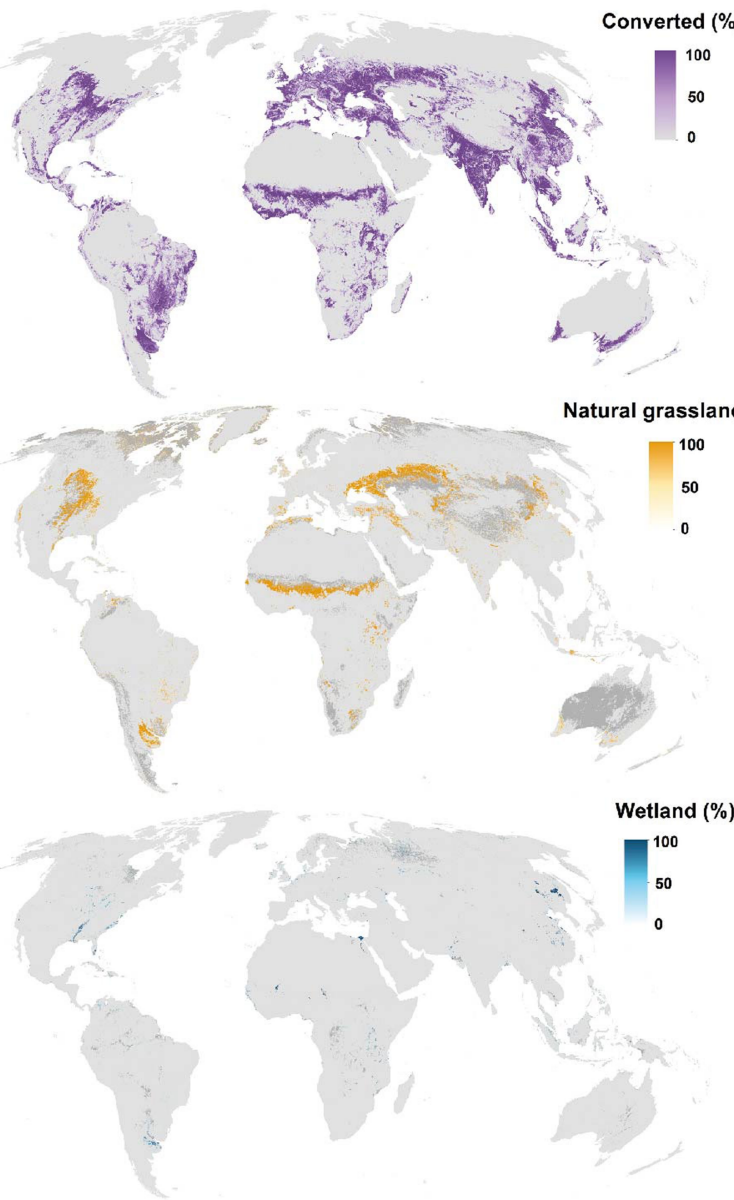

Extended Data Fig. 1 | Converted lands and their estimated original ecosystem type. a, Percentages of converted areas in each planning unit; current croplands and pasturelands are included as potentially restorable areas. b-f, Percentages of converted lands within each original ecosystem b
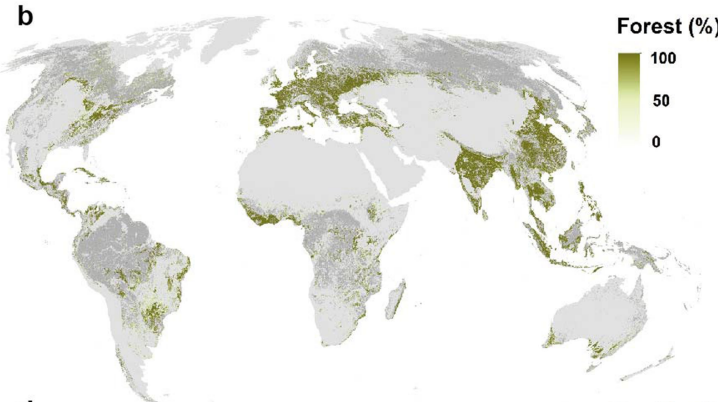

d
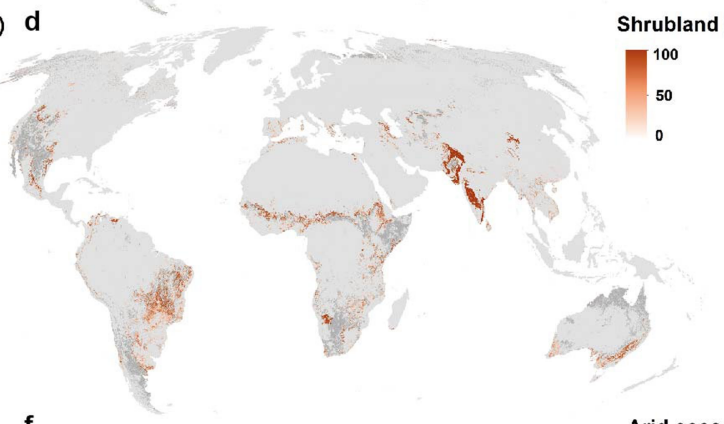

f
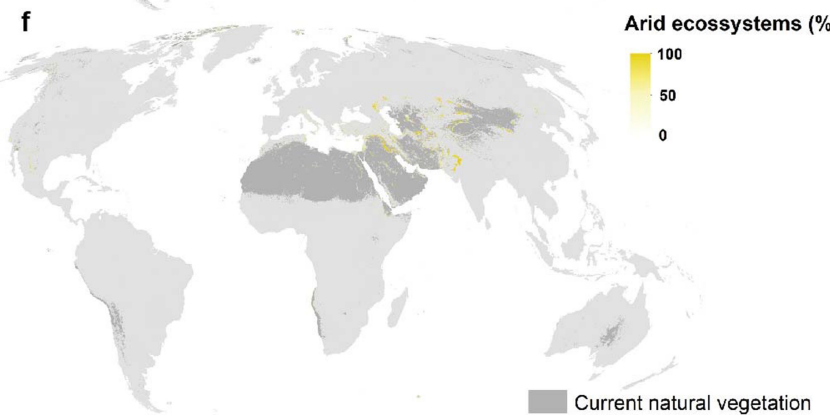

type: forests (b), natural grasslands (c), shrublands (d), wetlands (e) and arid areas (f). Areas in darker grey in $\mathbf{b}-\mathbf{f}$ represent the current extent of each ecosystem type. 

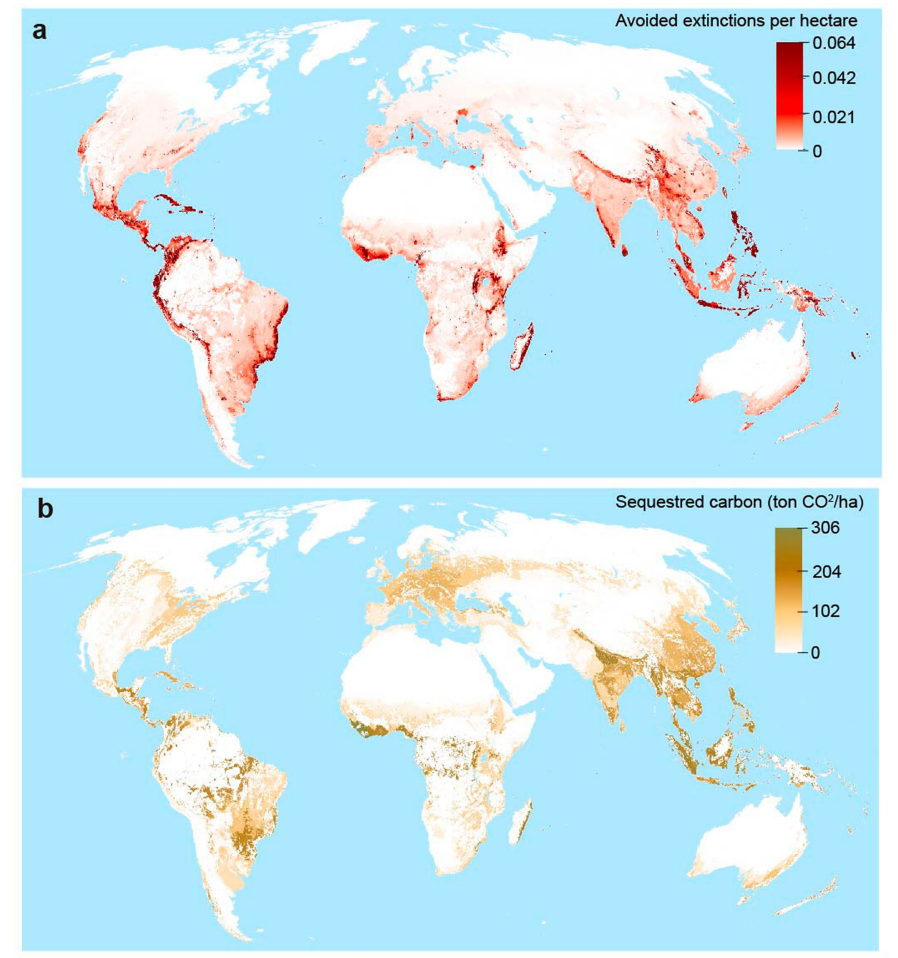

c

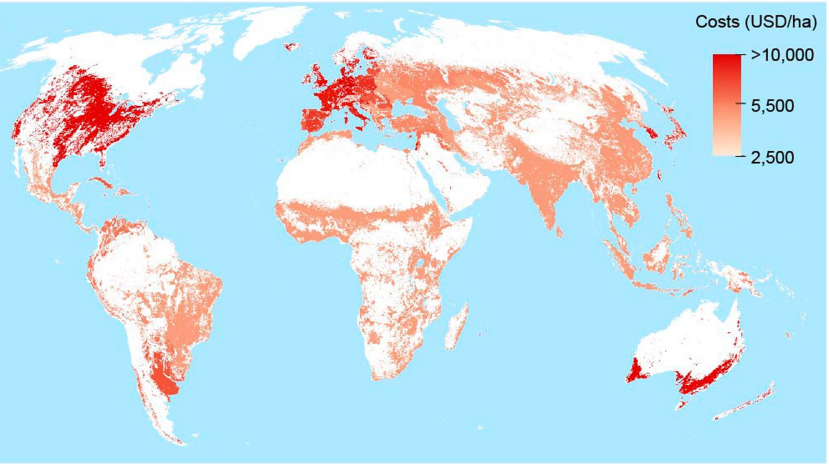

Extended Data Fig. 2 | Benefits of ecosystem restoration for biodiversity conservation, the mitigation of climate change and associated costs. $a$, Benefits for biodiversity were calculated as the number of avoided extinctions per hectare for all species combined. The map represents the starting situation with current vegetation cover before any restoration takes place. b. Benefits for climate change are calculated as the difference between the potential carbon stored after ecosystem restoration and the carbon currently stored in the agricultural lands. 'Stock' refers to carbon in the above- and belowground biomass and down to $30 \mathrm{~cm}$ in the soil, include above and belowground biomass and soil carbon sequestration. c, Costs consist of opportunity costs, based on the foregone agricultural benefits of areas allocated for restoration, and restoration implementation costs. 


\section{Article}

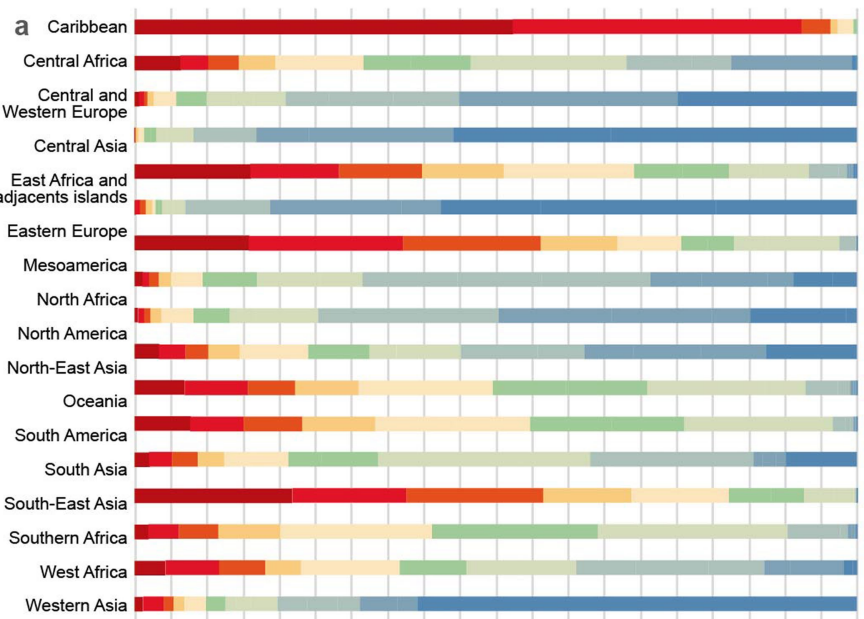

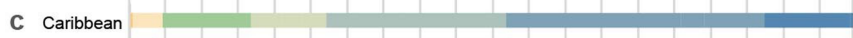
Central Africa

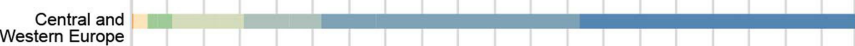
Central Asia

East Africa and adjacents islands

Eastern Europe

Mesoamerica

North Africa

North America

North-East Asia

Oceania

South America

South Asia

South-East Asia

Southern Africa

West Africa

Western Asia

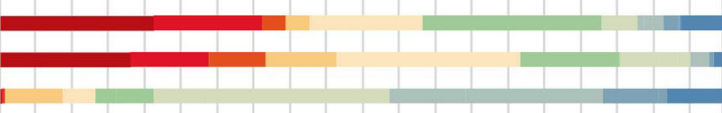

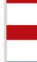
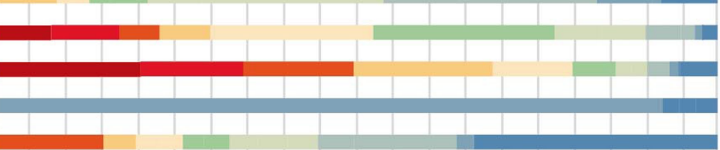

1
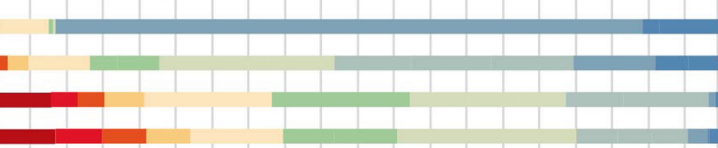

+
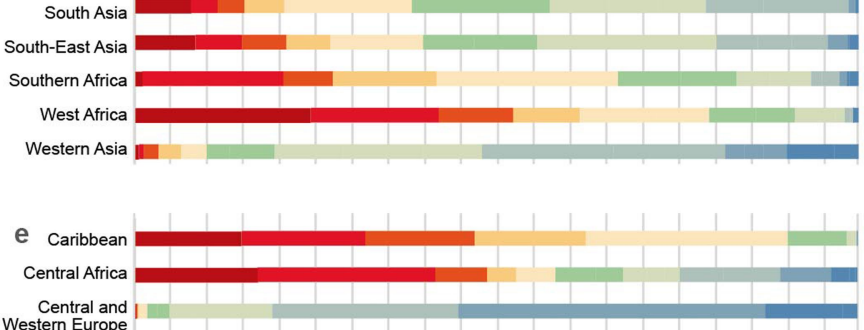

Central and
Western Europe

Central Asia I

\begin{tabular}{|l|l|l|l|l|l|l|l|l|}
\hline East Africa and \\
adjacents islands
\end{tabular}

Eastern Europe

Mesoamerica

North Africa

North America

North-East Asia

$$
\text { Oceania }
$$$$
\text { South America }
$$

South Asia

South-East Asia

Southern Africa

West Africa

Western Asia

$$
\begin{array}{rllllllllll|}
0 & 0,1 & 0,2 & 0,3 & 0,4 & 0,5 & 0,6 & 0,7 & 0,8 & 0,9 & 1
\end{array}
$$

Extended Data Fig. 3 | Areas potentially available for restoration and their relative priority across subregions. a-f, For each of the 17 subregions of IPBES, the horizontal bars show their relative priority percentile for the main scenarios focused on biodiversity (a), climate change mitigation (b), minimizing costs (c), biodiversity and climate change mitigation (d) and all three criteria (e); the last panel (f) shows absolute areas. South America has the greatest extent of converted lands that are relatively evenly distributed in the
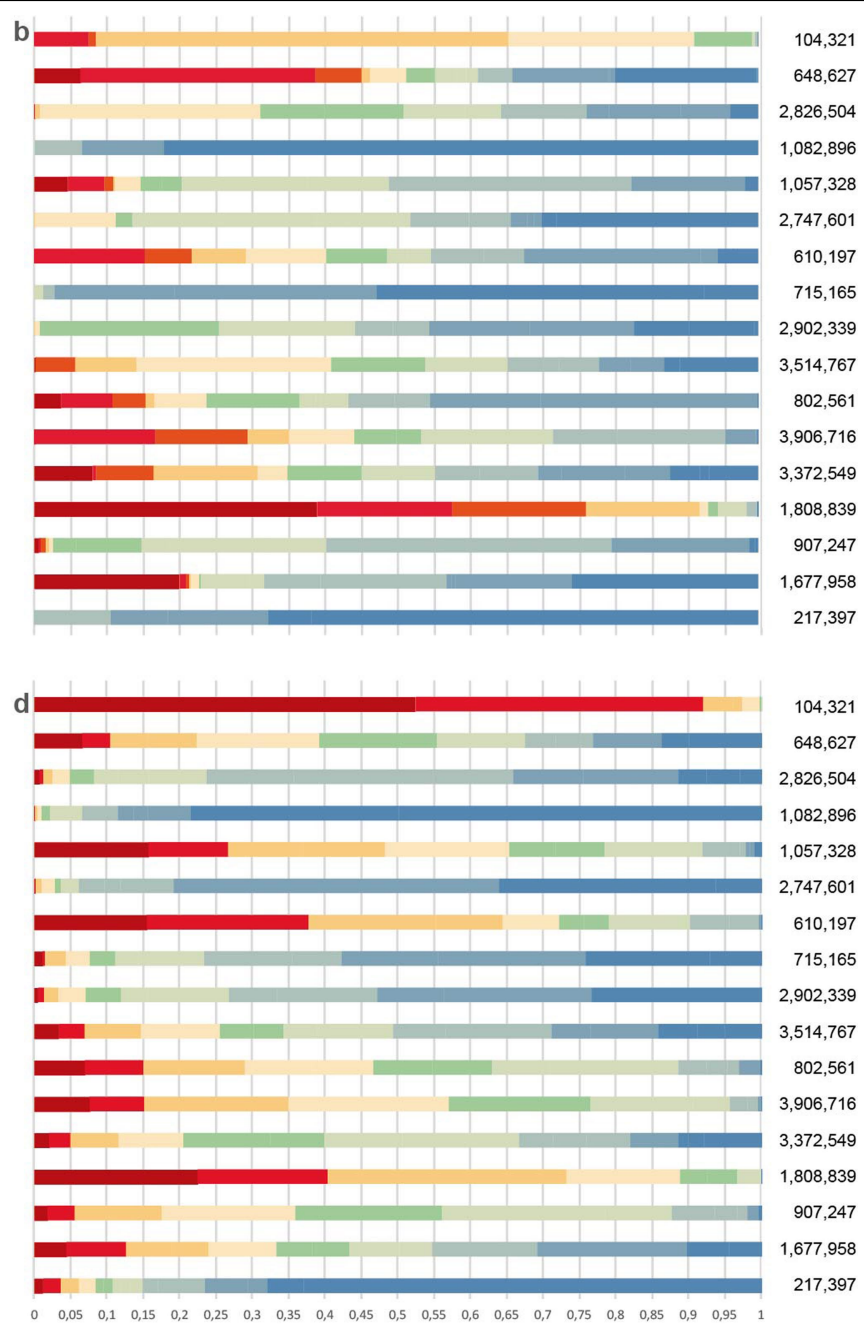

$\mathbf{f}$

I $\mid 104,321$

매 648,627

\begin{tabular}{|l|l||}
\hline 11 & $2,826,504$
\end{tabular}

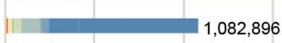

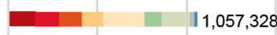

\begin{tabular}{|l|l|l|l|}
\hline 1 & $2,747,601$ \\
\hline
\end{tabular}

|| || 610,197

II 715,165

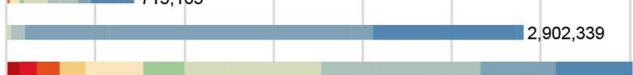

Priority for restoration

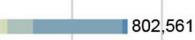

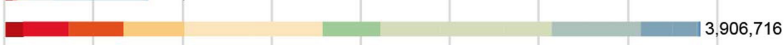

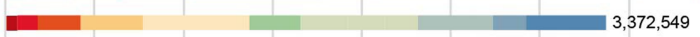

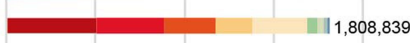

| 1907,247

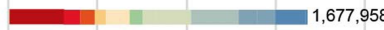

IIII) 217,397

$\begin{array}{llllllllll}0 & 0,5 \mathrm{M} & 1 \mathrm{M} & 1,5 \mathrm{M} & 2 \mathrm{M} & 2,5 \mathrm{M} & 3 \mathrm{M} & 3,5 \mathrm{M} & 4 \mathrm{M}\end{array}$

top $50 \%$ of global priorities, whereas the Caribbean has the smallest extent of areas potentially available for restoration-but almost all of them are in the top $10 \%$ of global priorities. The patterns in relative priority for restoration for each subregion change substantially across the different restoration scenarios, which further highlights the importance of using multicriteria optimizations that take into account several benefits of restoration simultaneously. 


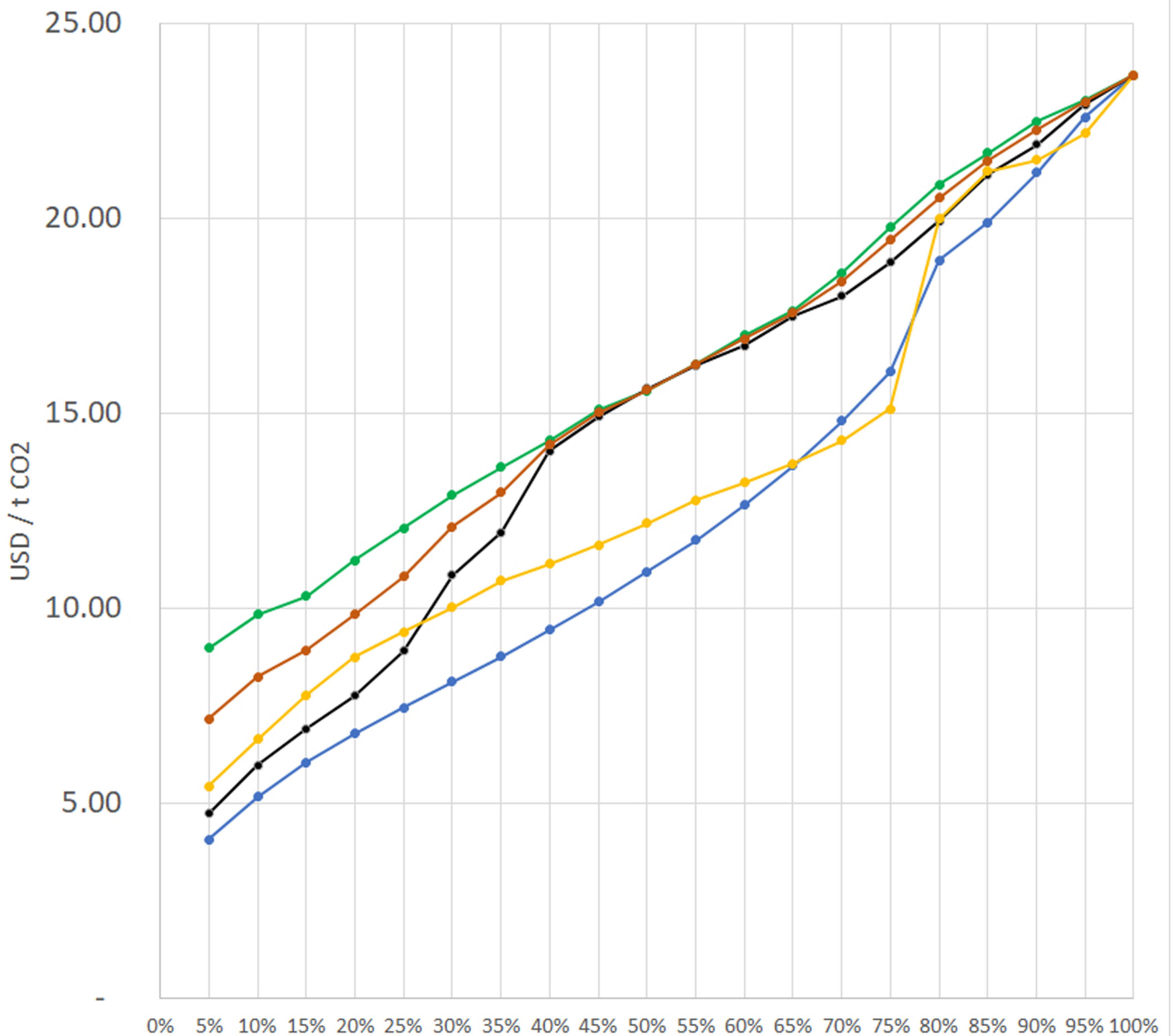

$\begin{array}{ll}\square \text { Biodiversity } & \text { Climate } \\ \text { Multiple Benefits } & \text { Min. Costs }\end{array}$

Extended Data Fig. 4 | Cost-efficiency of climate change mitigation for main scenarios. The curves show, for the 5 main scenarios and across 20 targets ranging from $5 \%$ to $100 \%$, the carbon value required to cover both opportunity and restoration costs. These results underscore the cost effectiveness of restoration as a climate mitigation option, as carbon values are in the lower range of low and medium mitigation costs according to the IPCC ${ }^{1}$. 


\section{Article}

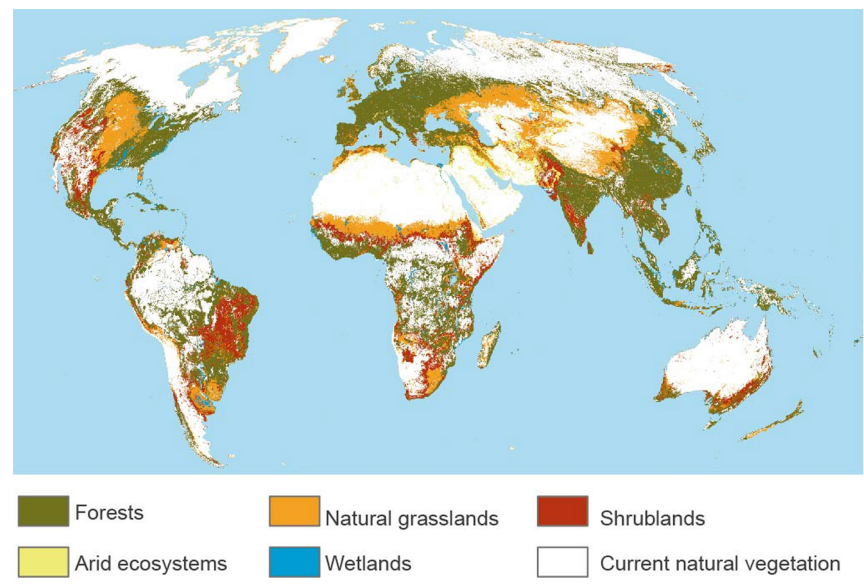

Extended Data Fig. 5 | Distribution of major ecosystem types that could be restored. Dominant estimated predisturbance ecosystem type in each cell; for the fraction of each ecosystem type per cell, see Extended Data Fig.1. 

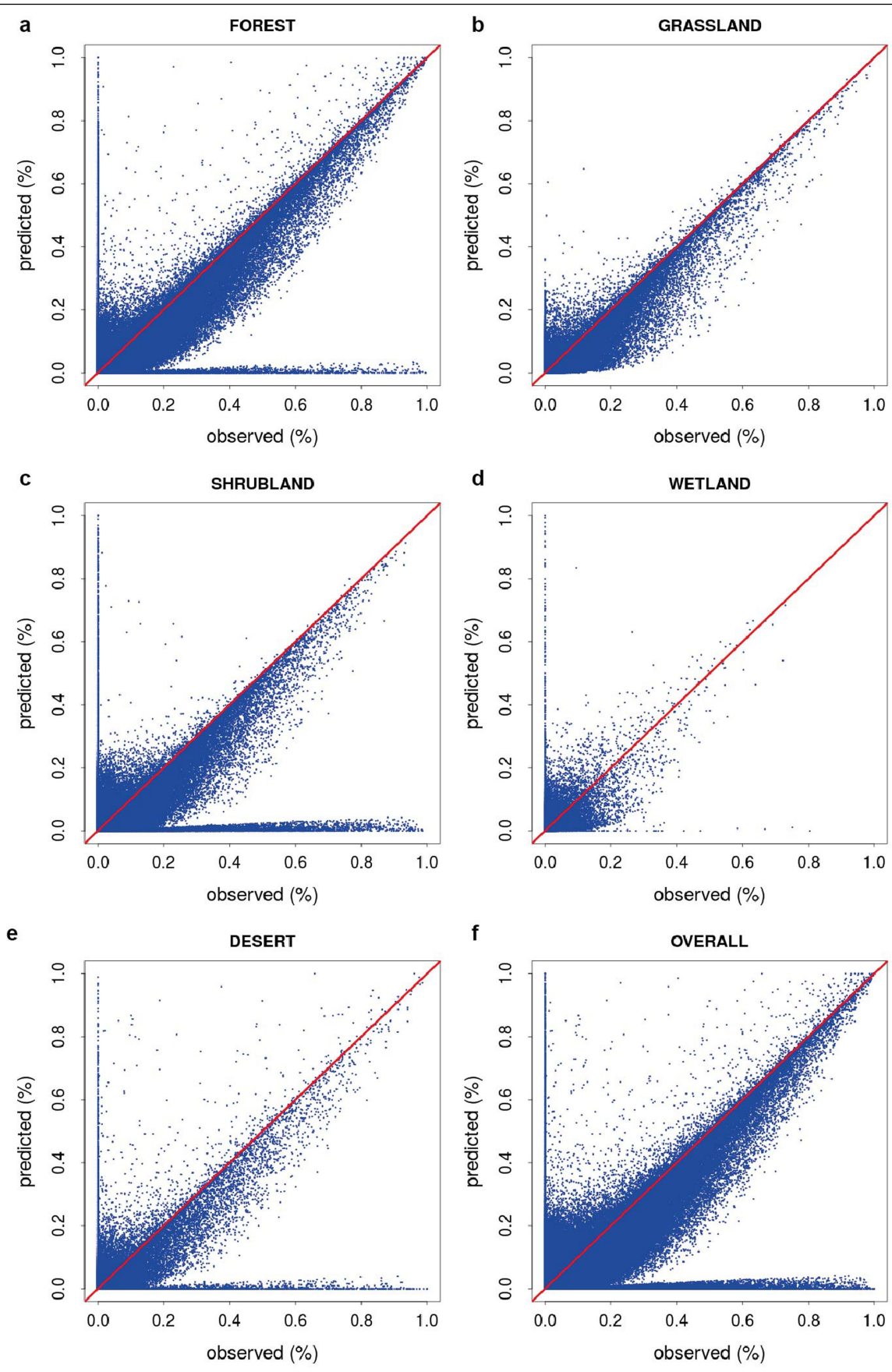

Extended Data Fig. 6 | Accuracy of original ecosystem-cover predictions. a-f, The accuracy of the predictions of the original proportion of each ecosystem type in each planning unit was quantified using the root mean square error (r.m.s.e.). To better understand any heterogeneity in prediction accuracy, we calculated the r.m.s.e. separately for each of the five land-cover

classes (forest, grassland, shrubland, wetland and desert) in addition to the overall r.m.s.e. Overall, predictive accuracy was excellent (total r.m.s.e 6.73\%,f) with relatively little variation among the five land-cover types: forests, $4.0 \%$ (a); grasslands, $1.7 \%(\mathbf{b})$; shrublands, $4.3 \%(\mathbf{c})$; wetlands, $1.2 \%(\mathbf{d})$; and arid areas, $2.6 \%(\mathbf{e})$. 


\section{Article}

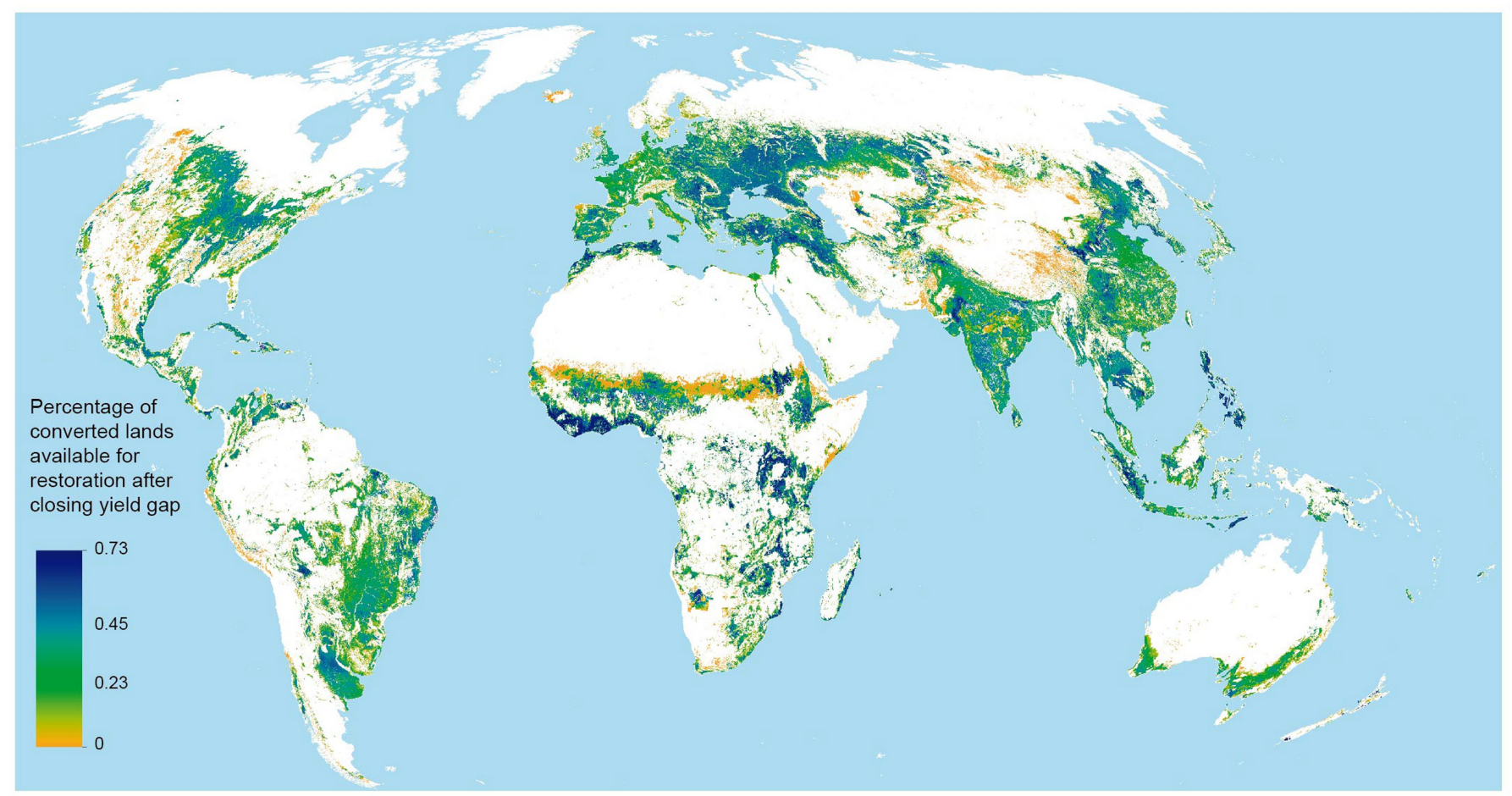

Extended Data Fig. $7 \mid$ Fraction of converted lands available for restoration after closing yield gaps. Combining yield gaps for croplands and pasturelands, the map indicates the fraction of a planning unit that could be spared if $75 \%$ of its yield gap were to be closed. 


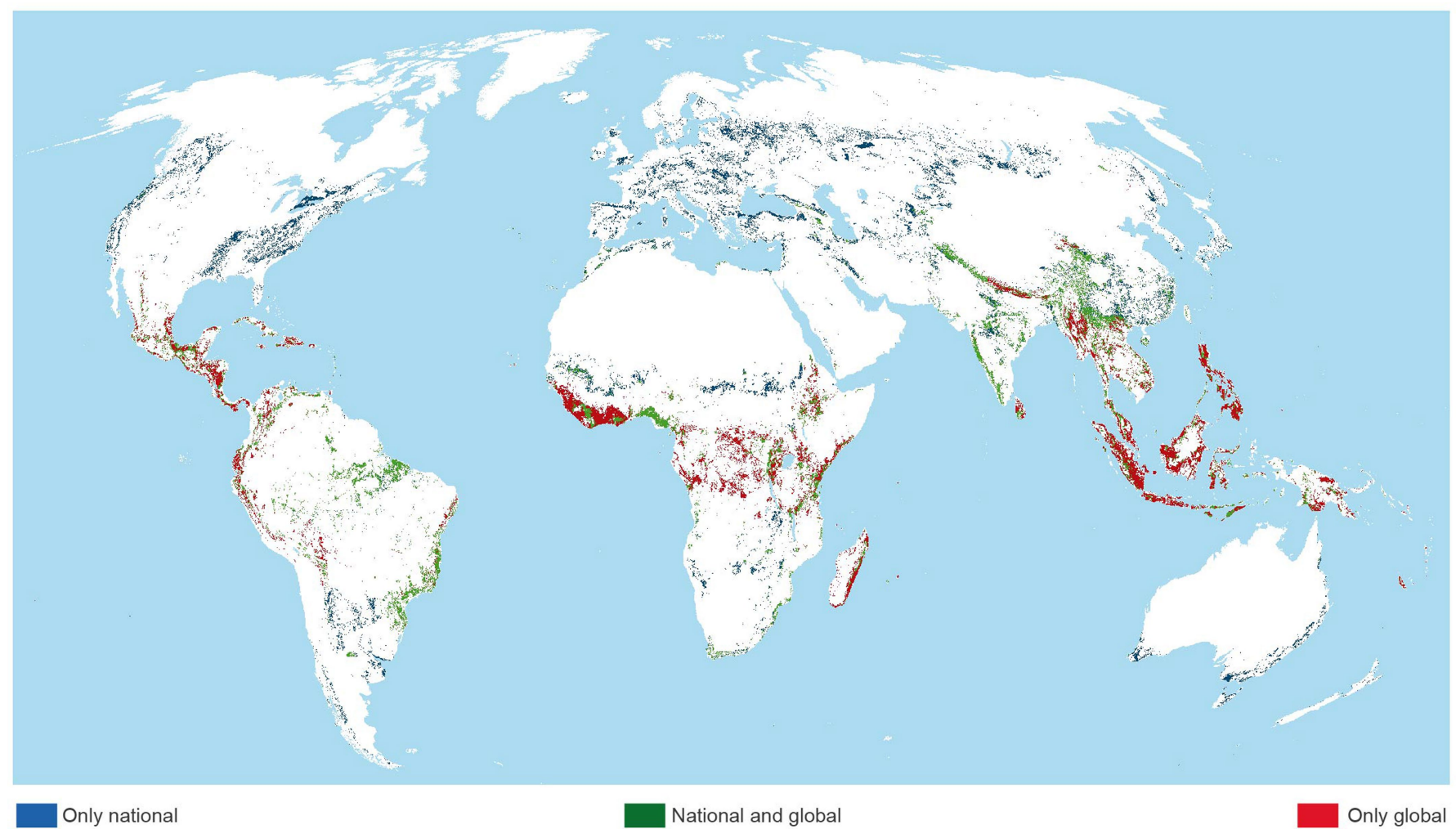

Extended Data Fig. 8 | Global and national priority areas for restoration. For the multiple benefits scenario and $15 \%$ restoration target, areas in green are selected both in the globally unconstrained scenario and in a scenario constrained by national boundaries; areas in red are selected only in the global scenario and areas in blue are selected only in the national version of the scenario. A substantial fraction (69\%) of global priority areas would not be restored using uniform national targets. As most of these areas are in lower-income countries, the results reinforce the role that international cooperation mechanisms such as REDD+ can have in achieving cost-effective global outcomes through restoration. 
a

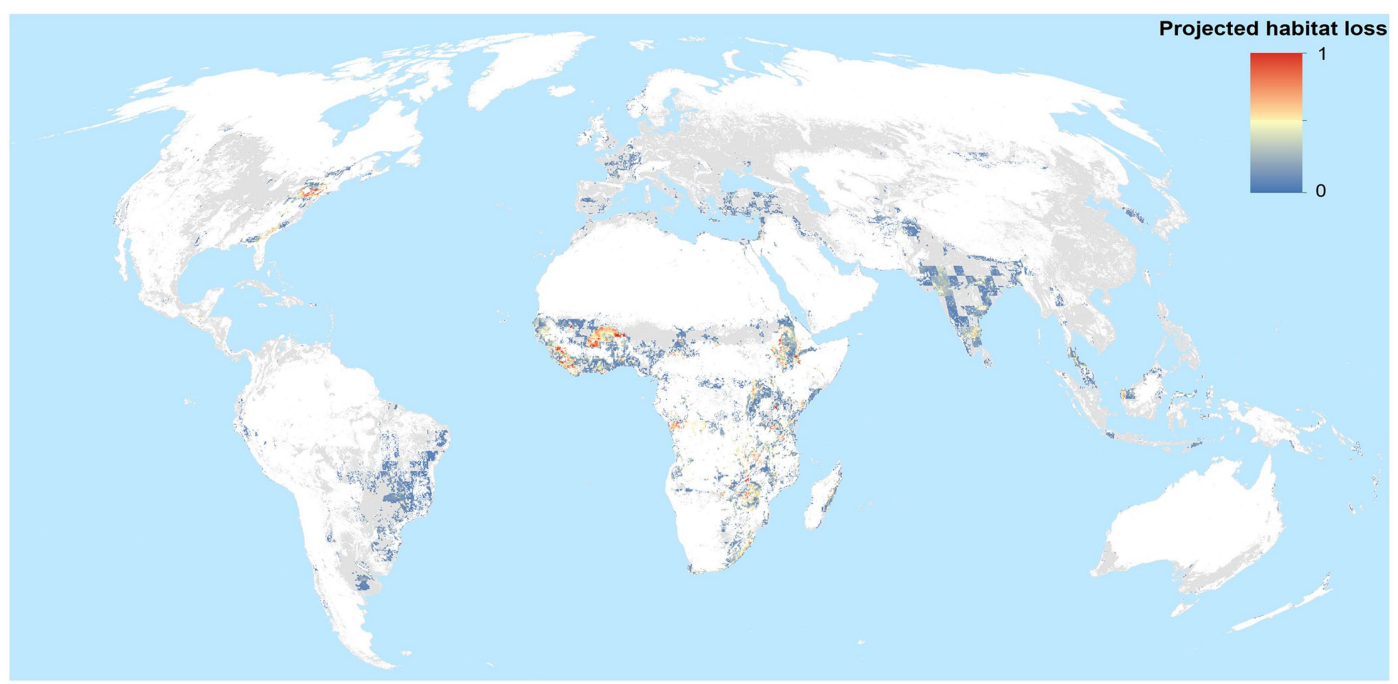

b
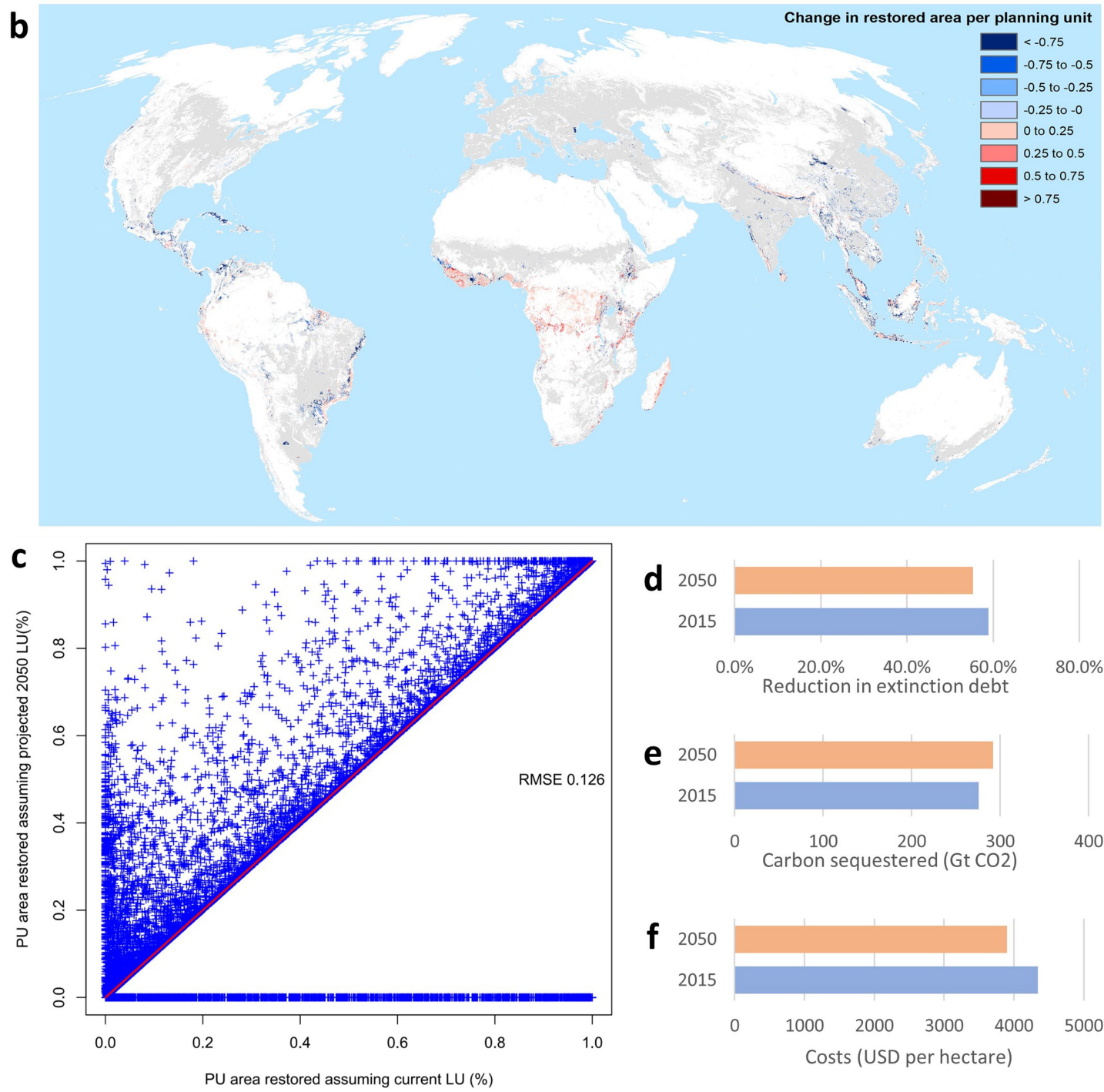

d 2050

2015

$0.0 \% \quad 20.0 \% \quad 40.0 \% \quad 60.0 \%$

$80.0 \%$

e 2050

2015

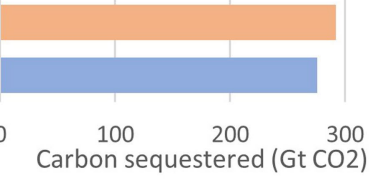

400

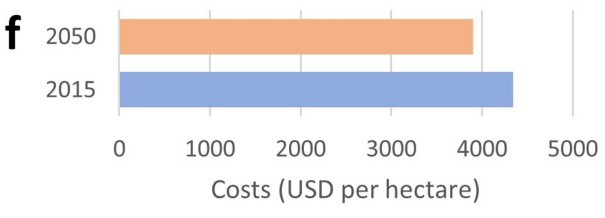

Extended Data Fig. 9 | Sensitivity analysis with future land-use change. $a, b$, In the pessimistic regional rivalries SSP 3 scenario $^{83}$, substantial conversion would happen until 2050 (a), and-as a consequence-some priority areas would shift towards newly converted areas of high endemic and threatened biodiversity that are also rich in carbon, in particular in Africa (b).c-f, Despite this, the restored fraction in each planning unit would be very similar to those

based on 2015 land-use (c) (r.m.s.e. $=13 \%$ ), and 2050 outcomes for biodiversity (d), climate (e) and costs (f) would be within the uncertainty range of 2015 estimates. Although the reduction in extinction debt would be slightly lower in 2050 (55\% versus $60 \%$ ), the extinction debt itself would be $25 \%$ higher $(10 \%$ versus $8 \%$ in 2015), so absolute extinctions avoided would be higher. 


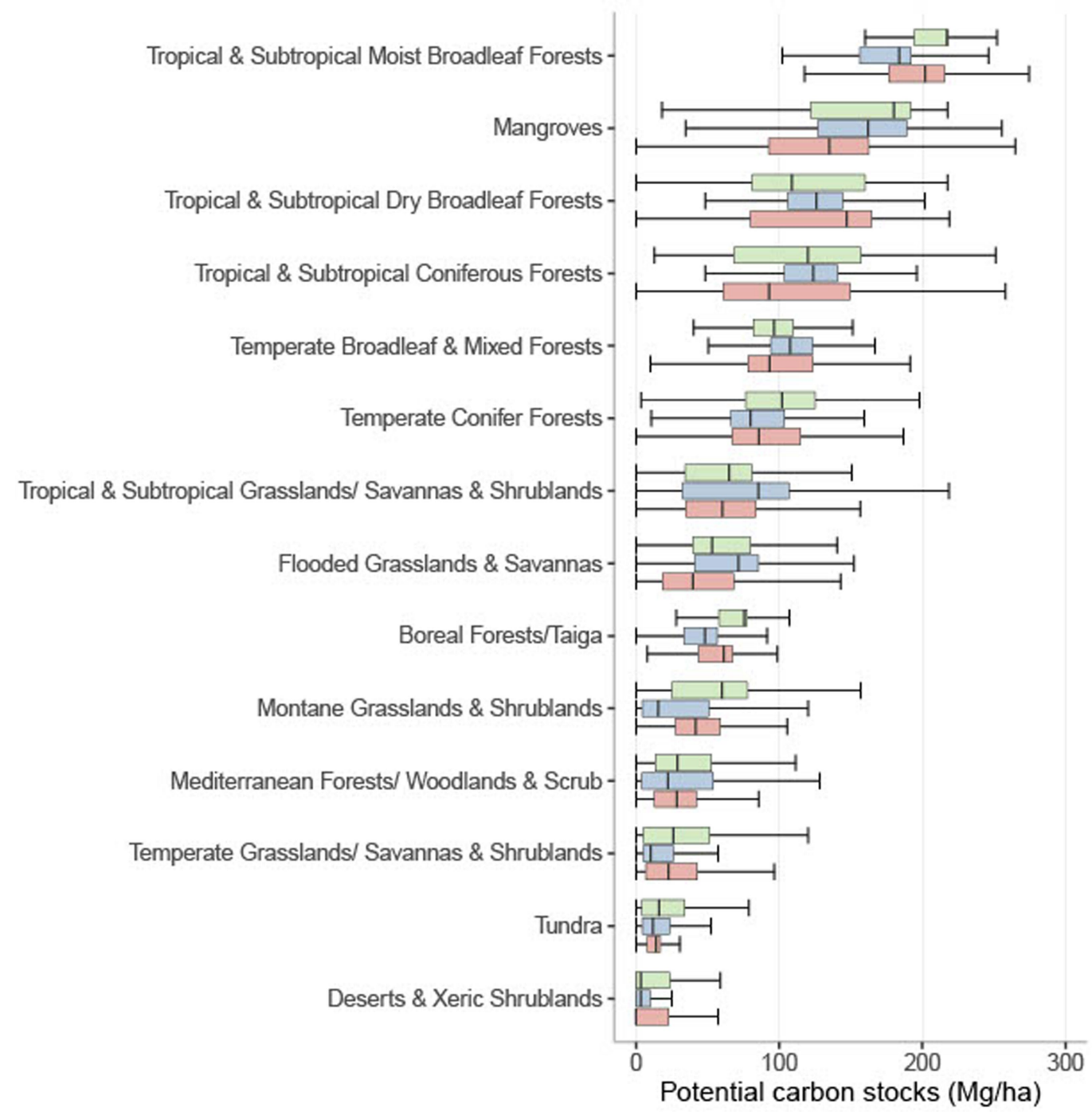

Extended Data Fig. 10 | Comparisons between potential biomass carbon stocks calculated in this study and other estimates. Comparisons between our estimates of potential carbon stocks in biomass (above and below-ground) and estimates from ref. ${ }^{24}$ : Forest Resources Assessment (FRA)-related map
(FAO) and remote-sensing based map. Box plots are based on pixel-level estimates of carbon stocks per ha in each biome, have the same sample size (pixels) across maps, and show the median (vertical lines), the interquartile range (bounding boxes) minimum and maximum values (whiskers). 


\section{Reporting Summary}

Nature Research wishes to improve the reproducibility of the work that we publish. This form provides structure for consistency and transparency in reporting. For further information on Nature Research policies, see our Editorial Policies and the Editorial Policy Checklist.

\section{Statistics}

For all statistical analyses, confirm that the following items are present in the figure legend, table legend, main text, or Methods section.

n/a Confirmed

$\bigotimes$ The exact sample size $(n)$ for each experimental group/condition, given as a discrete number and unit of measurement

Х $\square$ A statement on whether measurements were taken from distinct samples or whether the same sample was measured repeatedly

$\square$ The statistical test(s) used AND whether they are one- or two-sided

X $\square$ Only common tests should be described solely by name; describe more complex techniques in the Methods section.

Х $\square$ A description of all covariates tested

Х $\square$ A description of any assumptions or corrections, such as tests of normality and adjustment for multiple comparisons

$\square$ A full description of the statistical parameters including central tendency (e.g. means) or other basic estimates (e.g. regression coefficient)

A full description of the statistical parameters including central tendency (e.g. means) or other basic estima
AND variation (e.g. standard deviation) or associated estimates of uncertainty (e.g. confidence intervals)

$\triangle$ For null hypothesis testing, the test statistic (e.g. $F, t, r$ ) with confidence intervals, effect sizes, degrees of freedom and $P$ value noted

Give $P$ values as exact values whenever suitable.

Х $\square$ For Bayesian analysis, information on the choice of priors and Markov chain Monte Carlo settings

Х $\square$ For hierarchical and complex designs, identification of the appropriate level for tests and full reporting of outcomes

$\backslash \square$ Estimates of effect sizes (e.g. Cohen's $d$, Pearson's $r$ ), indicating how they were calculated

Our web collection on statistics for biologists contains articles on many of the points above.

\section{Software and code}

Policy information about availability of computer code

\section{Data collection No software was used for data collection}

Data analysis The software used to find exact solutions to this LP problem was R Symphony version 0.1-28, available online: http://R-Forge.Rproject. org/projects/rsymphony/

$\mathrm{R}$ codes developed for and used in this analysis are available upon request from the corresponding author.

R package Hmisc was used to calculate carbon stocks (Hmisc: Harrell Miscellaneous; R Package Version 4.1-1)

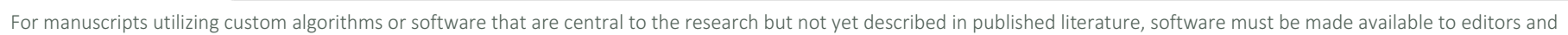

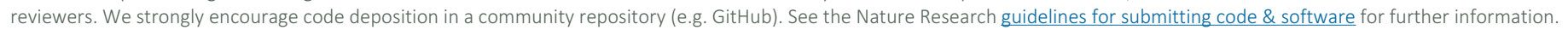

\section{Data}

Policy information about availability of data

All manuscripts must include a data availability statement. This statement should provide the following information, where applicable:

- Accession codes, unique identifiers, or web links for publicly available datasets

- A list of figures that have associated raw data

- A description of any restrictions on data availability

All input datasets are available from the references cited.

Publicly available ones include:

GAEZ: http://www.fao.org/nr/gaez/en/

HYDE: ftp://ftp.pbl.nl/hyde/

SoilGrids: https://files.isric.org/soilgrids/latest/data/ 


\section{Field-specific reporting}

Please select the one below that is the best fit for your research. If you are not sure, read the appropriate sections before making your selection.

Life sciences

\section{Ecological, evolutionary \& environmental sciences study design}

All studies must disclose on these points even when the disclosure is negative.

Study description

In this study, we applied a multi-criteria optimization framework, PLANGEA, to identify global priority areas for restoration and quantify trade-offs and synergies across biodiversity, climate change mitigation and costs. To do so, we: i) estimated current converted areas worldwide and their original (prior to human settlement) ecosystem type; (ii) estimated potential long-term restoration benefits for climate change mitigation and (iii) biodiversity in these areas; (iv) estimated costs; (v) implemented a multicriteria optimization algorithm based on Linear Programming (LP); and (vi) simulated different global restoration scenarios based on area targets.

Research sample
To build the current land use and land cover map (CLULC) map, we used the European Space Agency "Climate Change Initiative" (ESA CCI) land use and cover maps from 1992 and 2015, with 300 × 300 m pixel size.
As the ESA CCI map does not distinguish cultivated from natural grasslands, we used the Terrestrial Ecoregions of the World and the Gridded Livestock of the World v2.0 datasets to classify each pixel into natural (not needing restoration) or cultivated grasslands (potentially restorable pasturelands).
The Terrestrial Ecoregions of the World was also used as base of geographical zone to the extrapolation of mean carbon stock values from remaining native vegetation to restorable areas.
We modelled the change in extinction risk for 5,012 mammals, 6,515 amphibians and 11,121 bird species, totalling 22,648 species. Species distribution maps were accessed from the IUCN Data Portal.
We computed the opportunity costs of agriculture and cultivated pastures separately. For agriculture, the data was obtained from the IMPACT model, to get equilibrium-price estimates for 31 commodities in their SSP2 scenario with no climate change considered ("SSP2-NoCC"). The commodities were selected based on data availability for their current and potential productivity, as obtained from GAEZ database. For each commodity selected, we computed the present net value (NPV) of one ton of their produce for 40 years using a discount rate of $5 \%$ for our central estimate.
For pasture, we used the stocking rates data from the Gridded Livestock of the World v2.0. We consider pasture to include only the planning units with stocking rates in the range between 0.1 to 20 heads of cow per hectare, assumed to be compatible with pasture- based production. We used the values of Animal Yield per country from the IMPACT model to convert the stocking rate from head per ha to tons of produced beef per ha/year.
We estimated areas potentially spared for restoration compatible with maintaining current levels of agricultural production. For croplands, we used yield gaps based on yields attainable without irrigation (rainfed) from the GAEZ database. For pasturelands, based also on rainfed fodder grass productivity from the GAEZ database, we estimated the yield gap for extensive pasturelands systems.

Sampling strategy

No primary data was collected and no sampling was performed

Data collection

No primary data collection was performed, and the secondary datasets used are listed above.

Timing and spatial scale

No data collection was performed

Data exclusions

No data were excluded from the analyses

Reproducibility

The findings can be reproduced using the datasets and codes developed, all either publicly available or available upon request

Randomization

No data collection was performed

Blinding

No data collection was performed, and blinding not applicable to the modeling approach used

Did the study involve field work? $\square$ Yes $\bigotimes$ No

\section{Reporting for specific materials, systems and methods}

We require information from authors about some types of materials, experimental systems and methods used in many studies. Here, indicate whether each material, system or method listed is relevant to your study. If you are not sure if a list item applies to your research, read the appropriate section before selecting a response. 
Х $\square$ Antibodies

\ $\square$ Eukaryotic cell lines

\ $\square$ Palaeontology and archaeology

$\backslash \square$ Animals and other organisms

\ $\square$ Human research participants

\ $\square$ Clinical data

\ $\square$ Dual use research of concern
X $\square$ ChIP-seq

Х $\square$ Flow cytometry

Х $\square$ MRI-based neuroimaging 